EUROPEAN CENTRAL BANK

WORKING PAPER SERIES

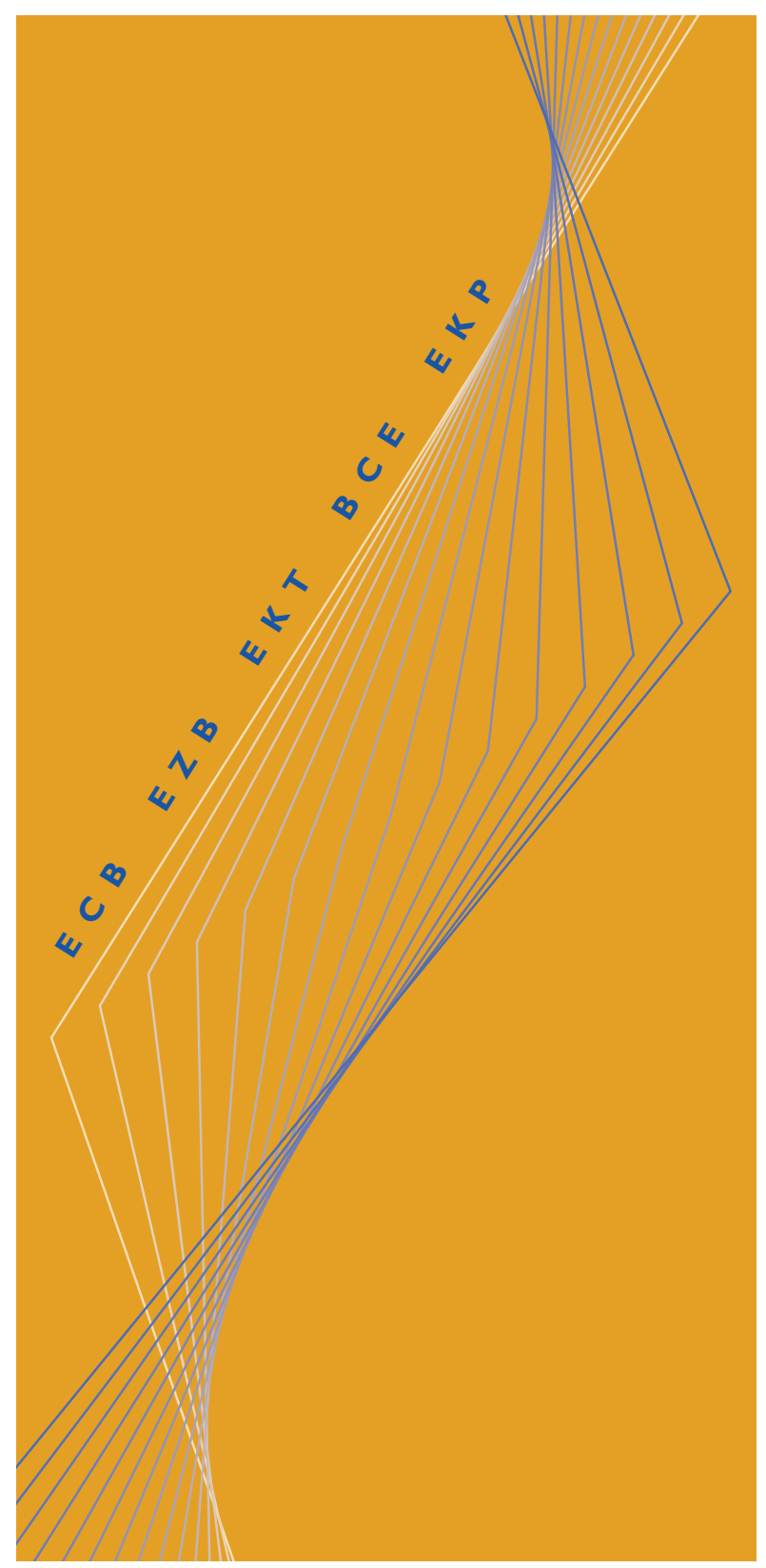

WORKING PAPER NO. 8

INFLATION ZONE

TARGETING

\author{
BY \\ ATHANASIOS ORPHANIDES \\ AND \\ VOLKER WIELAND
}

OCTOBER I 999 


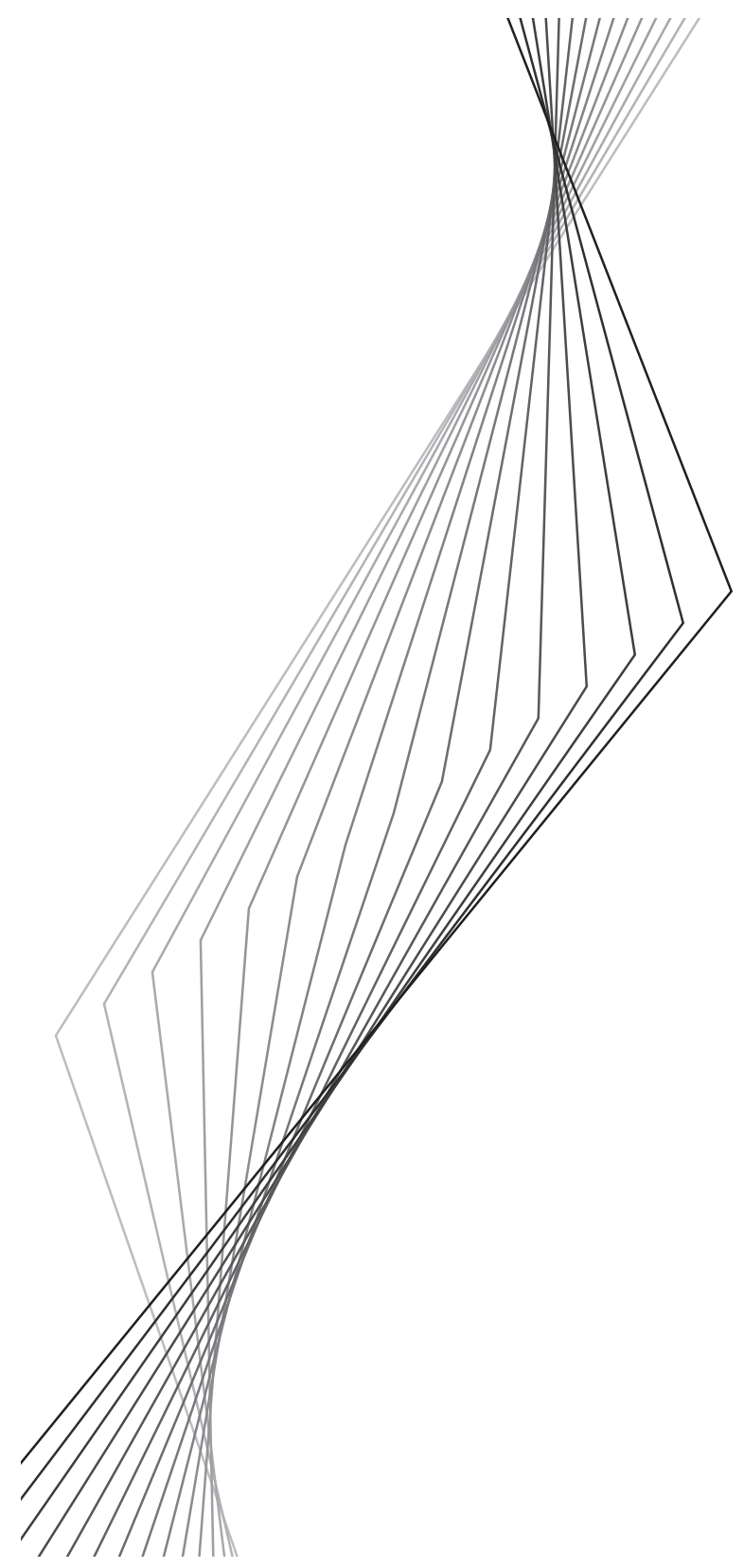

WORKING PAPER NO. 8

\title{
INFLATION ZONE \\ TARGETING
}

\author{
BY \\ ATHANASIOS ORPHANIDES \\ AND \\ VOLKER WIELAND \\ OCTOBER 1999
}

* Prepared for the International Seminar on Macroeconomics, INSEAD, Fontainbleau, France, June 18-19, 1999. Both authors are at the Board of Governors of the Federal Reserve System. This paper was written while Volker Wieland was a consultant at the European Central Bank. The opinions expressed are those of the authors and do not necessarily reflect views of the Board of Governors of the Federal Reserve System or the European Central Bank. Helpful comments by Ignazio Angeloni, Vitor Gaspar, Alexander Jung, Harald Uhlig, Frank Smets, Oreste Tristani, Ken West and seminar participants at the NBER-EER 1999 International Seminar on Macroeconomics at INSEAD, the European Central Bank and the Tinbergen Institute in Rotterdam are greatly appreciated. Any remaining errors are of course the sole responsibility of the authors. 
(C) European Central Bank, 1999

$\begin{array}{ll}\text { Address } & \text { Kaiserstrasse } 29 \\ & \text { D-60311 Frankfurt am Main } \\ & \text { GERMANY } \\ \text { Postal address } & \text { Postfach } 160319 \\ & \text { D-60066 Frankfurt am Main } \\ & \text { Germany } \\ \text { Telephone } & +496913440 \\ \text { Internet } & \text { http://www.ecb.int } \\ \text { Fax } & +496913446000 \\ \text { Telex } & 411144 \text { ecb d }\end{array}$

All rights reserved.

Reproduction for educational and non-commercial purposes is permitted provided that the source is acknowledged.

The views expressed in this paper are those of the author and do not necessarily reflect those of the European Central Bank.

ISSN 1561-0810 


\begin{abstract}
We study optimal monetary policy design in a simple model that deviates from the linear-quadratic paradigm and provides a rationale for the practice of inflation zone targeting. We show that the presence of either zone-quadratic preferences or a zonelinear relationship between inflation and economic activity provides strong incentives to deviate from conventional linear policies. We calibrate the model based on parameters for the U.S. and the Euro area and employ a numerical dynamic programming algorithm to derive the optimal policies. With this algorithm, we examine the role of uncertainty, model structure and relative preference towards economic stability in determining the width of the implied targeted inflation zone.
\end{abstract}

KEYWORDS: Inflation targeting, price stability, optimal monetary policy.

JEL Classification System: E31, E52, E58, E61 


\section{Introduction}

Over the past decade, a number of central banks around the world have announced inflation targets and have adopted an explicit inflation targeting framework for monetary policy. Well-known examples of countries with inflation targeting central banks are Canada, New Zealand, Sweden and the U.K.. An expanding literature has discussed the practical experience with inflation targeting and provided formal evaluations (see, for example, Haldane (1995), Leiderman and Svensson (1995), Svensson (1997, 1999a,b,c,d), Bernanke and Mishkin (1997) and Bernanke, Laubach, Mishkin and Posen (1999)). Based on this experience and analysis, some authors have also advocated the adoption of such an inflation-targeting framework by the Federal Reserve for the U.S. and by the European Central Bank for the Euro area.

For the most part, formal, quantitative evaluations of monetary policy in pursuit of an inflation target have been based on linear models of the economy with a quadratic objective function for the policymaker. Although appropriate in some cases, this approach does not fully capture the actual practice of inflation-targeting central banks. Most of these central banks tend to emphasize containing inflation within a target range rather than aiming for a point target. Fundamentally, a monetary policy that focuses on containing inflation within a zone implies a different response to shocks depending on whether inflation is within the zone or outside of it. This difference in policy responsiveness at the margin is inconsistent with the conventional linearquadratic framework which implies that the optimal policy rule is linear. By contrast, a target range invariably suggests a nonlinearity in the policy response function. Such target ranges are often motivated by the existence of uncertainty in the process of inflation. But optimal policies in the conventional linear-quadratic framework are invariant to such uncertainty. Thus, it may be necessary to entertain alternatives to the linear-quadratic framework in order to improve our understanding of the rationale and actual practice of inflation targeting.

In this paper, we investigate motives that can accommodate the observed emphasis on inflation zones rather than point targets and evaluate the performance of such a policy under uncertainty. Our analysis is normative in nature, simply investigating rationales as to why it may be sensible for central banks to pursue policies with inflation zone targeting characteristics. Although we draw from actual inflation zone targeting experience for motivation, we do not attempt to provide empirical evidence 
supporting the theory at this stage.

We consider two alternatives that depart from the conventional linear-quadratic framework in order to motivate inflation zones. First, we allow for a zone-quadratic objective on the part of the policymaker, that is a loss function which assigns quadratic loss to inflation deviations outside an explicit target zone and implies a near zero loss as long as inflation is contained within the zone. As a consequence, if the policymaker assigns at least some weight to output stabilization, the output objective will dominate at times when inflation is within the zone but will recede in importance when inflation is outside the zone. Such preferences would also be consistent with an apparent tendency of central banks to "put out fires," that is to react to inflation primarily when it becomes a problem but concentrate on other objectives when inflation is under control. ${ }^{1}$

Second, we consider the possibility of nonlinearities in the short-run inflation-output tradeoff. More specifically, we allow for the possibility that inflation is essentially stable for a range of output gaps and only increases or decreases materially when the output gap is outside this range. Translated into unemployment Phillips curve terms, this implies that instead of a well defined unique NAIRU there exists a range of unemployment rates over which inflation remains essentially stable. Such a "thick" NAIRU implies a concave-convex-shaped short-run inflation-output tradeoff. As we explain, this shape may be motivated based on the recent debate in the empirical literature over convexity versus concavity of the Phillips curve. ${ }^{2}$

After showing that these departures from the linear-quadratic framework induce an optimal policy rule that exhibits a target zone for inflation, we proceed to investigate the implications of uncertainty for inflation-zone targeting. It is well known that additive uncertainty, such as uncertainty due to unexpected demand and price shocks, has no effect on the optimal policy rule in the conventional linear-quadratic framework. This result is typically referred to as certainty-equivalence. Inflation targeting central banks however often emphasize the role of uncertainty in relation to target ranges

\footnotetext{
${ }^{1}$ Bernanke and Mishkin (1992), for instance, suggest that policymakers appear to pursue multiple objectives by shifting a large part of their attention to "the variable that is currently 'in crisis' " (p. 186).

${ }^{2}$ See for example Eisner (1997), Laxton, Rose and Tambakis (1999), Turner (1995) and others for estimates of alternative non-linear Phillips curves. Filardo (1998) has recently investigated the concave-convex-shaped Phillips curve using U.S. data. For a discussion of theoretical motivations for concave and convex Phillips curves see Stiglitz (1997) and Dupasquier and Ricketts (1998).
} 
for inflation and suggest that the choice of a target range over a point target is influenced by the degree of uncertainty they face. In our framework with non-quadratic preferences or a nonlinear inflation-output tradeoff we find that uncertainty due to unexpected shocks has important effects on the width of the target zone and on the relative size of the policy response inside and outside the zone. For example, under uncertainty the optimal policy does not respond mechanically only when inflation falls outside the zone. Instead, as we illustrate, it is optimal to respond to inflation deviations already within the zone and more aggressively if inflation continues to drift outside the zone. Furthermore, in the case of the zone-linear Phillips curve, the width of the target zone actually increases with the variance of inflation shocks.

Our framework of analysis is a simple macroeconomic model of inflation, output and interest rates with adaptive expectations. Such models have been widely used in the above literature on monetary policy and inflation targeting, but typically the main focus has been on linear versions with quadratic objectives. We parameterize this model using alternatively data for the U.S. and for the Euro area. We compute the dynamically optimal monetary policies using a dynamic programming algorithm that can accommodate non-linearities in the economic structure, non-quadratic preferences and uncertainty. Our analysis of inflation zone targeting also relates in some respects to the literature on exchange rate target zones (see, e.g. Krugman 1991). Similar to the investigation of the dynamic behavior of exchange rates when the central bank attempts to maintain the exchange rate within an explicit zone in that literature, our analysis provides information on the dynamic behavior of inflation with policy that has zone characteristics. However, there are important differences. First, unlike exchange rates the control of inflation is much less direct so strict control of inflation within a fixed zone, even if it were desired, would not be feasible. And second, our objective is to formally explore the rationale for adopting policies with zone characteristics while the emphasis in the case of exchange rate zones is to investigate the dynamics once a target zone is imposed on the economy.

The remainder of this paper proceeds as follows. Section 2 discusses the actual practice of inflation-targeting central banks in a bit more detail. Section 3 presents the linear-quadratic model that we use as a benchmark for comparison. In section 4 we depart from the linear-quadratic model by considering zone-quadratic preferences as a motive for target zones. Section 5 motivates a target zone based on a nonlinear Phillips curve. Parameter estimates of the basic model using U.S. and Euro area data 
are discussed in Section 6. Section 7 studies the impact of uncertainty and presents a comparison of optimal policies in the nonlinear model based on U.S. and Euro area parameter estimates. Section 8 concludes and the numerical dynamic programming algorithm that is used for computing dynamically optimal policies is described in the appendix.

\section{Zone versus point targets: policy practice}

In addition to announcing numerical inflation targets, the inflation-targeting central banks have adopted a complete policy framework that provides a strategy for achieving their stated goals. This framework has been described in many publications of the respective central banks and speeches of the policymakers. Very useful and detailed reviews of the inflation-targeting frameworks of New Zealand, Canada, the U.K., Sweden and several other countries have been provided by Bernanke et al. (1999) and Leiderman and Svensson (1995). Here we simply review one aspect of the respective country's inflation targeting framework - namely the choice of a target range versus a point target for inflation and how this choice is motivated.

New Zealand: In 1990, New Zealand became the first country to adopt a formal inflation targeting framework. The inflation target is typically stated as a range rather than as a point target. The Minister of Finance and the Governor of the Reserve Bank negotiate and publish a Policy Target Agreement (PTA) that defines specific targets by which monetary policy performance during the Governor's term can be measured. The first PTA in March 1990 defined price stability as annual inflation within a 0 to $2 \%$ range. Every 6 months the Reserve Bank publishes a Monetary Policy Statement. Starting with a target range of 3 to $5 \%$ in 1990, subsequent Monetary Policy Statements defined a path toward price stability by changing the target range to 2.5 to $4.5 \%$ in December 1991, $1.5 \%$ to $3.5 \%$ in December 1992 and 0 to $2 \%$ in December 1993 . The 0 to $2 \%$ target of price stability was intended to be a true zone, with a "hard" floor and ceiling but with no special emphasis on the mid-point (see Nicholl and Archer, 1992). At the end of 1996 the target zone was widened from $0 \%$ to $2 \%$ to $0 \%$ to $3 \%$ to avoid excessively activist policy responses that would be required to contain inflation in such a narrow band. In 1997 Governor Brash noted "The tension is between, on the one hand, choosing a target range which effectively anchors inflation expectations at a low level but which is so narrow that it provokes excessive policy activism and risks loss of credibility by being frequently exceeded; and on the other, a target range which does a less effective job of anchoring inflation 
expectations, but which requires less policy activism and protects credibility by being rarely breached" (cited in Bernanke et al., 1999, p. 113).

Canada: The Bank of Canada became an inflation-targeter one year later in 1991. Its target definition is similar to the definition of the Reserve Bank of New Zealand, in that it is stated as a range rather than a point target. A target range of $+/-1 \%$ was set around a midpoint of $3 \%$ at the end of $1992,2.5 \%$ by mid-1994 and $2 \%$ by the end of 1995. Bernanke et al. (1999) note that while the objective to be targeted was the mid-point of the range, in practice, the Bank of Canada never aggressively sought to move inflation from the outer bands toward the midpoints, even when actual inflation lingered at or below the target floor for an extended period. For example, in 1995 the Bank's Deputy Governor Charles Freedman, wrote "With inflation having fallen to the bottom of the bands during the past couple of years and seeming likely to remain there in the near future, the emphasis in the revised targets was put on the inflation bands, thereby indicating that the Bank cannot control inflation all that closely" (Freedman, 1995, p. 24). Governor Thiessen also made clear that containing inflation within the zone would involve some countercyclical policy by stating "When weakening demand threatens to pull inflation below the target range, it will be countered by monetary easing" (Thiessen, 1996, cited in Bernanke et al., 1999, p. 123.)

United Kingdom: The adoption of an inflation target in the U.K. was a reaction to the exit from the European Monetary System in 1992. It was announced by the Chancellor of the Exchequer, Norman Lamont, who three weeks later invited the Governor of the Bank of England to publish a quarterly Inflation Report. In May 1997 the Bank of England obtained operational independence. Initially the U.K. set a target range for inflation. Since May 1997 the target has been expressed as a point, but with $1 \%$ thresholds on either side. Once inflation breaches a target threshold, the Bank of England is required to provide a formal explanation to the government. In a recent speech, the chief economist of the Bank, John Vickers, directly addressed the question of how these thresholds may affect the policymakers' loss function. He argued that Monetary Policy Committee (MPC) members are no graphophobes, that is, they have no fear of writing a letter to the Chancellor to explain why the inflation target has been missed by more than $1 \%$ (see Vickers, 1998, p. 370).

Sweden: Like the U.K., Sweden adopted an inflation target after the 1992 EMS crisis. As of 1993 the Riksbank defined the target of price stability as keeping the 
annual change in consumer prices at $2 \%$, with a tolerance interval of $+/-1 \%$. The principal reason for the tolerance interval is inflation uncertainty, which reflects the imperfect control of monetary policy over the inflation rate. Furthermore, the Riksbank has repeatedly emphasized that target breaches that are perceived to be transitory would not require policy action. For example, in 1997 the Deputy Governor, Lars Heikensten, stated, "It is because of temporary effects that the average level of inflation in 1996 is outside the Riksbank's target interval. As a rule, the interval surrounding the target figure should suffice to absorb changes of this type in the composition of inflation" (Heikensten, 1997, cited in Bernanke et al., 1999, p. 197). In June 1998 the Riksbank's Inflation Report noted "Various kinds of transitory effects have been particularly marked in certain periods. ... The factors that exert transitory effects on inflation and should therefore disregarded in the construction of monetary policy are not self-evident and may also differ from case to case," (Sveriges Riksbank, 1998, p. 41).

This review of actual policy practice suggests that most inflation-targeting central banks consider target ranges or tolerance intervals for inflation a useful policy tool within their inflation targeting framework. ${ }^{3}$. Furthermore, some of these central banks have explicitly stated that the upper and lower bands of such a target range play a more important role in their strategy than the mid-point and have differentiated between policy responses inside and outside the target range. In all cases the target range or tolerance interval is loosely motivated by the fact that inflation outcomes are uncertain, that is, due to the possibility of unforeseen shocks the central bank cannot control the inflation rate perfectly. Nevertheless, inflation targeting central banks have made clear that they expect the long-run average of inflation to be about equal to the mid-point of the target range or tolerance interval, which suggests that policy responses above and below the range are expected to be symmetric. Finally, policymakers have typically emphasized that target ranges are not pursued in a mechanical manner. For example, some have pointed out that even when inflation breaches one of the bands, an activist policy response may not be required if the breach is expected to be of a transitory nature.

Given the wide use of target ranges or zones among inflation-targeting central banks,

\footnotetext{
${ }^{3}$ Another interesting example is Australia. Rather than choosing a wider target range or a single point target the Reserve Bank pursues a "thick" point target of "around 2-3\% over the medium term", (Stevens and Debelle, 1995, p.82.)
} 
we believe that it is important to differentiate between strategies of inflation zone and inflation point targeting. To understand the essence of an inflation zone targeting strategy it is instructive to first abstract from uncertainty completely and simply examine how a policymaker would pursue his long-run inflation objective, defined as a numerical target $\pi^{*}$, when faced with an initial inflation level that differs from this target in a deterministic setting. In its purest form, an inflation zone targeting strategy differentiates the required policy stance depending on whether the inflation rate deviates substantially from the target or is fairly close to it. When inflation deviates substantially from its target, the policymaker takes action towards bringing inflation back closer to its target. However, when inflation is fairly close to its target the policymaker opts not to actively pursue further improvements. This strategy implicitly defines an inaction zone for inflation. Letting $z$ denote the width of this zone, the strategy implies that as long as current inflation is within the range $\left(\pi^{*}-\right.$ $z / 2, \pi^{*}+z / 2$ ) policy will simply aim to maintain inflation at its current setting. And, of course, as long as inflation is maintained in this range, the policymaker will attempt to maintain a zero output gap and avoid an inflationary or disinflationary impetus from aggregate demand. ${ }^{4}$

In light of the experience of inflation-targeting central banks and based on formal analyses of inflation targeting strategies, a number of authors have advocated that the Federal Reserve and the European Central Bank respectively adopt an inflation targeting framework for monetary policy. As to the European Central Bank, the announcement of a precise, quantitative definition of a medium-term price stability objective is already a central feature of the ECB's strategy. The ECB has defined price stability in terms of "price increases of less than two percent". This definition excludes deflation and is symmetric. ${ }^{5}$ However, the ECB has also made clear that it does not follow a strategy of direct inflation targeting such as the central banks of New Zealand, Canada, Sweden and the U.K. nor a pure monetary targeting strategy. Neither of these strategies was judged fully adequate in light of the uncertainty due to potential structural changes in many economic relationships and the discontinuity in statistical information following the start of European Monetary Union. For a thorough discussion of the ECB's strategy and comparisons to inflation and monetary

\footnotetext{
${ }^{4}$ As we explain later on, implementing an inflation zone targeting strategy is more complex in practice, since uncertainty will have a crucial influence on the optimal policy response to inflation.

${ }^{5}$ Unlike the maximum, the minimum is not made explicit because of the absence of reliable evidence on the measurement bias that may be associated with the new Harmonized Index of Consumer Prices (HICP), (Angeloni et al. 1999).
} 
targeting the reader is referred to Angeloni, Gaspar and Tristani(1999).

While target ranges appear to be an important tool of inflation-targeting central banks, formal evaluations of inflation targeting have typically been based on linear or linearized models of the economy with a quadratic loss function for the central bank, which do not provide a rationale for the use of target ranges. Optimal policy in such a linear-quadratic framework responds linearly to output and inflation and other relevant state variables. Furthermore, uncertainty by itself provides no motive for an explicit zone, and uncertainty due to unforeseen additive shocks to inflation has no effect at all on the optimal policy response. Thus, the conventional linear-quadratic framework is at odds with the emphasis put on target ranges by inflation-targeting central banks. ${ }^{6}$ In the following section we present an example of such a linearquadratic model, which we will use as a benchmark in our analysis of inflation zone versus inflation point targeting.

\section{The L-Q Theory of Inflation Point Targeting}

We build a minimalist model of the economy following closely the structure of recent studies examining alternative disinflation strategies and efficient monetary policyparticularly the models in Ball (1999), Orphanides and Wilcox (1996), Orphanides (1998) and Svensson (1997). The two key variables in the policy decision process are inflation and output and the monetary policy instrument is the short-term nominal interest rate. Inflation is determined by an accelerationist Phillips curve and output follows a simple autoregressive process. For simplicity the dynamic structure of the economy is collapsed to a single lag of inflation and output and it is therefore appropriate to interpret the length of a period in our model to be rather long, perhaps as long as a year.

The model is chosen for its expositional simplicity and its usefulness for organizing our results in terms of key concepts frequently encountered in monetary policy discussions. However, this comes at a cost that we wish to make explicit at the outset. Specifically, our model is not directly based on microeconomic principles and optimizing foundations and abstracts from a number of elements that may be important

\footnotetext{
${ }^{6}$ Of course, uncertainty still affects inflation outcomes. Thus, central banks may want to communicate the changing degree of uncertainty associated with inflation forecasts, but rather by changing uncertainty bands as done by the Bank of England and Sveriges Riksbank rather than a fixed target range. Nevertheless, one could argue that a target zone may be a particularly simple way to communicate an unconditional confidence interval for the long-run to the public.
} 
in practice. ${ }^{7}$ By abstracting from the explicit modeling of expectations, for instance, we do not address the intricate interactions between policy design and expectations formation. We also avoid questions regarding credibility and reputation issues concerning the central bank and the commitment mechanism that might be required for adopting time-consistent optimal plans. Indeed, with our simplifying assumptions, the "commitment" and "no commitment" solutions to the policymaker's problem are identical and correspond to the dynamic programming solution. The main advantage of these simplifying assumptions is that we can focus on the computation of the dynamically optimal monetary policies using a dynamic programming algorithm that can accommodate non-linearities in the economic structure, non-quadratic preferences and uncertainty. Computation of such optimal policies in non-linear rational expectations models, by contrast, is decidedly more complex.

In every period, the policymaker sets the nominal interest rate, $R$, with the objective to maintain inflation, $\pi$, close to a desired target consistent with reasonable price stability, $\pi^{*}$, and output close to the economy's natural level-that is to keep the output gap, $y$, close to zero. ${ }^{8}$ To describe the policymaker's welfare loss during a period $t$ in terms of the economy's inflation and output performance we specify a per-period loss function, $l_{t}=l\left(\pi_{t}, y_{t}\right)$. In practice, since monetary policy operates with a lag, a policymaker setting policy during period $t$ can have relatively little influence on aggregate demand and inflation during the same period. As a result, it is more helpful to view the policy problem as one in which the policymaker sets the short-term nominal interest rate during period $t, R_{t}$, with an aim to influence the economy in period $t+1$ and in later periods. That is, the first per-period loss relevant for the policymaker's decision in period $t$ is $l_{t+1}$. With this in mind, and assuming that the policymaker discounts the future with a fixed discount factor $\beta$, we can view the policymaker's objective in period $t$ as to minimize the expected discounted sum of future per-period losses from $t+1$ onward:

$$
\mathcal{L}_{t}^{A}=E_{t}\left\{\sum_{s=0}^{\infty} \beta^{s} l_{t+1+s}\right\}
$$

The policymaker solves this problem subject to the dynamic structure of the economy. We will assume that the economy can be characterized recursively so that inflation and

\footnotetext{
${ }^{7}$ Clarida, Gertler and Gali (1999), Rotemberg and Woodford (1998) and Woodford (1999) offer examples of models with detailed micro-foundations.

${ }^{8}$ The short nominal interest rate we have in mind as serving the role of a policy instrument would correspond to the federal funds rate for the Federal Reserve, or the euro-overnight-indexaverage (eonia) rate for the European Central Bank, which refers to the weighted average of overnight (unsecured) rates reported by a panel of large banks in the Euro area.
} 
output in period $t+1,\left(\pi_{t+1}, y_{t+1}\right)$ are determined by just three factors: the state of the economy in the preceding period, that is, inflation and output, $\left(\pi_{t}, y_{t}\right)$; the policy choice in period $t, R_{t}$; and stochastic shocks to inflation and output, $\left(e_{t+1}, u_{t+1}\right)$, that are drawn from zero-mean, independent normal distributions in every period. Then, in period $t$, the policymaker's problem is to set the policy instrument, $R_{t}$, responding to current inflation and output developments, $\pi_{t}$ and $y_{t}$, so as to minimize the loss function (1).

In general this setup can accommodate a variety of alternative specifications of preferences and economic structures. However, it is not always straightforward to solve for the policymaker's optimal choice of the policy instrument $R_{t}$. The conventional model employs two additional assumptions regarding preferences and the structure of the economy that render the problem tractable, namely the assumptions of quadratic preferences and a linear economy. With these two convenient assumptions, analytical results from linear-quadratic (L-Q) control theory become applicable and the solution of the problem is greatly simplified.

Following the conventional setting, we endow the policymaker with symmetric preferences that are quadratic in both the deviation of inflation, $\pi$, from its desired target, $\pi^{*}$, and the output deviation from the economy's natural output level, $y$. The perperiod loss facing a policymaker in period $t+1, l_{t+1}$, can therefore be expressed as a weighted average of these two components:

$$
l_{t+1}=\omega\left(\pi_{t+1}-\pi^{*}\right)^{2}+(1-\omega) y_{t+1}^{2}
$$

This specification has two essential characteristics. First, the weight, $\omega$, which is assumed to be a fixed fraction between zero and one, reflects the relative weight a policymaker places on the objective of stabilizing inflation relative to the objective of stabilizing output. A weight approaching one would reflect a policymaker who places no value on output stabilization, that is an "inflation nutter" in the terminology of King (1997). A weight between zero and one is generally considered more consistent with the mandate of many central banks to not only maintain price stability but also facilitate economic growth and welfare over time. Second, the loss is minimized (and is equal to zero) when inflation and the output gap are at their respective bliss levels of $\pi^{*}$ and zero. This rules out a built-in inflationary bias in policymaker preferences which although present in some theoretical models is considered not applicable for 
the formulation of monetary policy by policymakers themselves. ${ }^{9}$

In our baseline linear structure, two equations describe the evolution of the economy:

$$
\begin{gathered}
\pi_{t+1}=\pi_{t}+\alpha y_{t+1}+e_{t+1} \\
y_{t+1}=\rho y_{t}-\xi\left(r_{t}-r^{*}\right)+u_{t+1}
\end{gathered}
$$

where $\alpha$ and $\xi$ are positive, $\rho \in[0,1), r^{*}$ is the natural real rate of interest and $e_{t+1}$ and $u_{t+1}$ are the zero-mean normally distributed shocks. The real interest rate is denoted by $r_{t}$ and defined as the short-term nominal interest rate $R_{t}$ minus inflation:

$$
r_{t} \equiv R_{t}-\pi_{t}
$$

The equation for the output gap reflects a tendency for output to revert to its natural level when monetary policy is "neutral," and to respond otherwise linearly to deviations of the real interest rate, $r_{t}$, from its natural rate, $r^{*}$, with a lag of one period. The equation for inflation represents a linear accelerationist Phillips curve. An implicit assumption in our specification is that demand pressures influence inflation changes contemporaneously. ${ }^{10}$ With this assumption, policy can have an effect on both output and inflation with a one period lag - that is after one year. This structure also proves convenient for two other reasons. As will become evident shortly, this timing allows a particularly simple analytical exposition because it permits a decoupling of the determination of the influences of current aggregate demand and current inflation conditions on the optimal setting of the policy instrument. In addition, with this structure, the solution to the static problem which applies to a policymaker who is only concerned about the per-period loss $l_{t+1}$ in the subsequent period retains the salient characteristics of the solution to the more general infinite horizon case. Finally, by concentrating on the short-term nominal interest rate as the policy instrument, we do not need to introduce a monetary aggregate explicitly in the model. An implicit money demand equation is present in the background, of course, providing a relationship between income, prices and interest rates which determines

\footnotetext{
${ }^{9}$ See the discussions by Blinder $(1997,1998)$, King (1997) and Vickers (1999).

${ }^{10}$ This differs from the timing adopted by Ball (1999) and Svensson (1997) who assume that aggregate demand influences inflation only with a one period lag. We chose the timing assumption embedded in Orphanides and Wilcox (1996) and Orphanides (1998) because although as an empirical matter we agree that aggregate prices do not appear to adjust instantaneously to changes in aggregate demand, it may not be sensible to rule out any such adjustment for a longer period of time. Since we interpret the length of a period to be fairly long we find the assumption of a contemporaneous response more appealing.
} 
the necessary money supply that the central bank needs to supply in every period to achieve the desired setting of the nominal interest rate.

The most direct way to solve this problem is by applying dynamic programming techniques. Assuming that the policymaker observes the current level of inflation, $\pi_{t}$, and the current output gap, $y_{t}$, without error during the period $t$, those two variables completely describe the state of the economy. Thus, the solution to the policymaker's problem implies an optimal policy reaction function that describes how the policymaker ought to set the policy instrument, $R_{t}$, in response to these two state variables:

$$
R_{t}=R\left(\pi_{t}, y_{t}\right)
$$

However, this problem can be recast in a simpler form that allows us to restate the policymaker's strategy in terms of a single state variable, which is current inflation, $\pi_{t}$.

To see this, observe that according to equation (4), in period $t$ the policymaker can determine the output gap in the subsequent period, $y_{t+1}$, by setting the nominal interest rate, $R_{t}$, up to the stochastic shock, $u_{t+1}$. Now let $\hat{y}_{t+1}$ denote the intended output gap that the policymaker attempts to achieve in period $t+1$. Equation (4) indicates that the policymaker can pursue this intended output gap by setting:

$$
R_{t}=r^{*}+\pi_{t}+\frac{\rho}{\xi} y_{t}-\frac{1}{\xi} \hat{y}_{t+1}
$$

The actual output gap can thus be written in terms of the policymaker's intention and the stochastic shock to the output equation as:

$$
y_{t+1}=\hat{y}_{t+1}+u_{t+1} \text {. }
$$

As a result the policymaker's choice in period $t$ can be restated in terms of the desired output gap for the subsequent period, $\hat{y}_{t+1}$. Since current period output, $y_{t}$, does not appear in either the inflation equation (3), or in the per-period loss, $l_{t+1}$, only one state variable remains, current inflation, $\pi_{t}$. Surely, as is clear from (6), knowing both state variables, $\pi_{t}$ and $y_{t}$, remains necessary for setting the nominal interest rate $R_{t}$ in order to achieve the desired output gap in period $t+1$. The dynamic optimization problem, however, can be solved in terms of a single state, $\pi_{t}$.

To solve this optimization problem we proceed to write the Bellman equation:

$$
V\left(\pi_{t}\right)=\min _{\hat{y}_{t+1}} E_{t}\left\{l_{t+1}+\beta V\left(\pi_{t+1}\right)\right\}
$$


where the inflation equation (3) determines the transition of the state from $\pi_{t}$ to $\pi_{t+1}$, equation (2) is employed for the per-period loss, $l_{t+1}$ and equation (7) is used to express the actual output gap in period $t+1$ in terms of the policy intention, $\hat{y}_{t+1}$, which we treat as the control variable. The expectation operator integrates over the distribution of the stochastic shocks, $e_{t+1}$ and $u_{t+1}$. As is well known, for our baseline linear-quadratic case, the value function, $V$, is quadratic in the state variables itself. With this information it is straightforward (though somewhat tedious) to obtain the solution for the optimal policy in closed form. This is:

$$
\hat{y}_{t+1}=\mu\left(\pi_{t}-\pi^{*}\right)
$$

where $\mu$ is a function of the parameters of the model. For the general case with a discount factor $\beta \in(0,1)$ the solution is:

$$
\mu=\frac{(1-w)(1-\beta)+\alpha^{2} w-\sqrt{\Psi}}{2 \alpha \beta(1-w)}
$$

where

$$
\Psi=\alpha^{2}\left[4(1-w) w+(\alpha w)^{2}\right]+(1-w)(1-\beta)\left[(1-w)(1-\beta)-2 \alpha^{2} w\right]
$$

The two limiting cases of myopic preferences, $\beta \rightarrow 0$, and no discounting, $\beta \rightarrow 1$, are of independent interest. The no discounting case, $\beta \rightarrow 1$, is of interest because then the policymaker's problem becomes equivalent to the minimization of the weighted asymptotic variances of inflation and output. This allows for discussions of policy in terms of the inflation and output variability tradeoff. ${ }^{11}$ In that case the expression for $\mu$ simplifies to:

$$
\mu_{(\beta \rightarrow 1)}=\frac{\alpha w-\sqrt{4(1-w) w+(\alpha w)^{2}}}{2(1-w)}
$$

The myopic case, $\beta \rightarrow 0$, provides a useful benchmark for comparisons if the policymaker in period $t$ attempts to minimize just the period $t+1$ loss, $l_{t+1}$. In that case, the problem collapses to a static one, in which the value function coincides with the per-period loss function. The resulting expression for $\mu$ is:

$$
\mu_{(\beta \rightarrow 0)}=\frac{-\alpha w}{\alpha^{2} w+(1-w)}
$$

As can be seen, the solution retains the salient characteristics of the general case with discounting. Because of this, examination of the myopic case becomes particularly

\footnotetext{
${ }^{11}$ Since its introduction by Taylor (1979), the practice of discussing policy using such variability tradeoffs has been adopted in a large number of both academic and policy studies. See for instance, the contributions in Taylor (1999).
} 
useful for comparisons with models that deviate from the L-Q framework since in such models an analytical solution may exist only for the myopic case and not for the general one.

It is important to note that although we chose to express the policymaker's problem for period $t$ in terms of the choice of the intended output gap in period $t+1$, this is merely a convenient analytical device and does not reflect on the relative weight the policymaker places on inflation versus output stabilization. Rather it reflects the constraint implicit in the Phillips curve. To see how, it is instructive to define $\hat{\pi}_{t+1}$ as the intended rate of inflation for period $t+1$ consistent with the policymaker's intended output gap, $\hat{y}_{t+1}$, that is reflected in the optimal policy decision taken during period $t$. Using the Phillips curve, it is immediate to see that:

$$
\hat{\pi}_{t+1}=\pi_{t}+\alpha \hat{y}_{t+1}
$$

Therefore, stating the policymaker's strategy in terms of the intended output gap and in terms of the intended inflation are equivalent. Stated in terms of intended inflation, the optimal policy (9) can be written as:

$$
\hat{\pi}_{t+1}=(1+\alpha \mu) \pi_{t}-\alpha \mu \pi^{*}
$$

This also illustrates that, in general, the policymaker's strategy will reflect a gradual attainment of the inflation target, $\pi^{*}$. Although the policymaker can attain this target within one period, in expectation, only an "inflation nutter" would choose to do so. In that case, i.e. when $\omega=1$, the optimal policy yields $\mu=-1 / \alpha$ and, therefore, $\hat{\pi}_{t+1}=\pi^{*}$, regardless of the level of current inflation.

Once the optimal choice of the intended output gap for $t+1$ is determined, equation (6) provides the optimal interest rate rule in terms of the two state variables, $\pi_{t}$ and $y_{t}$. In our baseline model this takes the form of the Taylor rule with a positive nominal interest rate response to the output gap and a response to inflation that exceeds one (note that $\mu<0$ ).

$$
R_{t}=r^{*}+\pi_{t}+\frac{\rho}{\xi} y_{t}-\frac{\mu}{\xi}\left(\pi_{t}-\pi^{*}\right)
$$

A pertinent characteristic of this strategy is that the optimal policy sets the interest rate, and thus the intended output gap, proportionally to the inflation gap, i.e. the inflation deviation from its desired target, $\pi^{*}$. In this sense, the optimal policy 
in the L-Q model requires the policymaker to pursue the price stability objective gradually but persistently. However large or small the inflation gap may be, this policy suggests that the policymaker should actively pursue policies towards closing it. And the intensity with which this objective is pursued is always proportional to the gap that is to be closed. Exactly because of this property, the L-Q framework appears unsuitable for investigating the rationale for inflation zone targeting policies. In the next two sections we investigate instead deviations from the L-Q framework that can help us understand the rationale for target zones.

A final important observation is that the optimal policy in the L-Q model is independent of the variance of the shocks to the output and inflation equations. Of course, this simply reflects the validity of the certainty equivalence principle in this setting. By contrast, as we shall see later on, the influence of uncertainty plays an important role in determining optimal policy once we deviate from the conventional L-Q framework.

Surely, the presence of uncertainty does affect the resulting inflation and output variability. With greater uncertainty, inflation will deviate more frequently and more substantially from its target, $\pi^{*}$. It is sometimes suggested that one potential role for an inflation range is as a communication device that can be employed by policymakers to acknowledge the imperfect control of inflation from period to period and provide an indication of the magnitude of this uncertainty. For instance, a range could be specified so as to reflect a one standard deviation band from the policymaker's intended inflation, $\hat{\pi}_{t+1}$. However, to serve this purpose, an inflation range would need to be adjusted period by period to reflect both changes in this uncertainty as well as changes in the policymaker's intended inflation rate, $\hat{\pi}_{t+1}$, which, from (13), changes period by period with actual inflation, $\pi_{t}$. But a more straightforward and transparent way to communicate such uncertainty would be by providing explicit information regarding the probability distribution of the policymaker's intended inflation rate, $\hat{\pi}_{t+1} \cdot{ }^{12}$ The potential for providing information regarding uncertainty within the

\footnotetext{
${ }^{12}$ The probability distribution presented in the form of a fan chart in the Bank of England's Inflation Report provides a nice example of this more straightforward and transparent way to communicate inflation forecast uncertainty. More recently, Sweden's Riksbank has also started publishing uncertainty bands that reflect the uncertainty about shocks that will affect the economy as well as uncertainty about both the qualitative and quantitative nature of the transmission mechanism (see Blix and Sellin (1998)). Of course, these uncertainty bands change over time and differ from the $+/-1$ percentage point tolerance band around the Riksbank's $2 \%$ target. However, because the inflation forecasts presented by the Bank of England and the Riksbank are conditioned on the assumption that the short-term nominal interest rate will remain unchanged, they do not exactly correspond to
} 
L-Q framework does not provide a very useful rationale for an inflation target range.

\section{Non-quadratic preferences and inflation zone targeting}

The first deviation from the linear-quadratic paradigm that we examine involves the policymaker's preferences. Specifically, we relax the assumption that the per-period loss faced by the policymaker is quadratic and instead examine an alternative that can provide a partial rationale for inflation zone targeting.

To be sure, a quadratic loss function may approximate the policymaker's preferences reasonably well around the point where the approximation is taken. But it does not follow that the same quadratic function can provide a reasonable approximation over the wide range of actual inflation experiences policymakers face over time. This is not meant to suggest that we can accurately uncover the correct functional form of the policymaker's preferences. We most certainly recognize the complexities involved in such a task. Rather, we want to illustrate how plausible alternatives to the quadratic preference paradigm may have rather different implications for the optimal policy response to small and large deviations of inflation from a point inflation target. In a sense, we wish to explore the possibility of a preference for inflation-zone targeting.

The intuition behind these alternatives is based on comparing the order of the cost of small departures of output from its bliss level and that of small departures of inflation from its target. If the former is larger than the latter, it may be sensible for the policymaker to ignore small deviations of inflation from its target rather than incur the higher order costs required to bring inflation back to its target. With a loss function that is quadratic in inflation and output, the order of costs for small deviations from target are equal (quadratic) for both inflation and output. But there are reasons to suspect that this may not be entirely realistic.

One reason is the indivisibility of labor employment decisions. For much of the workforce, employment is an all-or-nothing proposition. An individual may be either employed full-time or unemployed. Orphanides and Wilcox (1996) have argued that as a consequence of this indivisibility, even small deviations from full employment impose first order costs on a policymaker who aggregates over individual welfare. As a consequence, even if the loss function is quadratic in inflation deviations from its

our concept of the policymaker's intended inflation, $\hat{\pi}_{t+1}$, which also reflects the intended movements of the interest rate. 
desired target, the optimal policy exhibits inflation zone targeting characteristics. ${ }^{13}$

A second reason arises from the very rationale for valuing price stability. Typically, policymakers value maintaining inflation at a low and stable target such as zero, one or two percent, not because low inflation raises welfare in itself but because a low and stable inflation environment indirectly enhances welfare by promoting stable economic growth, and by reducing resource allocation distortions and inefficiencies. Consequently, these indirect costs of inflation must be understood and evaluated before forming a judgment regarding the functional form that best approximates the policymaker's loss with respect to inflation.

While there is wide-spread agreement on the deleterious effects of high inflation and rapid deflation, the effects of a marginal change in inflation near price stability are not as clear. ${ }^{14}$ As a result, it seems plausible to specify a per-period loss of inflation which allows for a range - instead of just a single point - over which the policymaker's loss is not materially influenced by marginal changes in inflation. For instance, we could entertain the possibility that the per-period losses at zero, one or two percent inflation are essentially equal to each other with the per-period costs rising only as inflation veers outside this range. It is important to clarify that this comparison applies only to the per-period loss from inflation, not the infinite discounted sum of per-period losses that the policymaker aims to minimize. Even if zero, one and two percent inflation are equally costly in any given period, a policymaker might still exhibit a preference for one percent over zero if that reduces the risk of veering into costly deflation in subsequent periods, and might still prefer one percent over two if that reduces the risk of veering into the higher levels of inflation that are clearly detrimental to the economy. Indeed, this distinction is critical for understanding the implications of this type of preferences for the practice of inflation zone targeting.

One way to model such a non-quadratic loss while simultaneously nesting the quadratic specification, (2), as a special case, is with the per-period loss:

$$
l_{t+1}=\omega Z\left(\pi_{t+1}-\pi^{*}, \zeta\right)^{2}+(1-\omega) y_{t+1}^{2}
$$

\footnotetext{
${ }^{13}$ Clarida, Gertler and Gali (1999) and Orphanides, Small, Wieland and Wilcox (1997) have investigated this mechanism further.

${ }^{14}$ Fischer and Modigliani (1978), and Fischer (1981) provide taxonomies of the costs of inflation. Orphanides and Solow (1990) document that theoretical arguments regarding the costs and benefits of inflation in the monetary growth literature are inconclusive. Empirical research by Clark (1997), Judson and Orphanides (1999), and Sarel (1996), suggests that moderate and high inflation have a negative effect on growth but finds no evidence of a clear relationship at very low levels of inflation.
} 
where $Z(. ; \zeta)$ is a zone-generating function that is approximately zero within a range of width $\zeta$ and linear outside this range. The following specification for $Z$, based on the sum of two hyperbolas, is a convenient tool for making this transformation:

$$
Z(x ; \zeta ; c)=x-\frac{1}{2} \sqrt{c+\left(x+\frac{\zeta}{2}\right)^{2}}+\frac{1}{2} \sqrt{c+\left(-x+\frac{\zeta}{2}\right)^{2}}
$$

Here, $\zeta$ is a parameter controlling the width of the zone generated by the function and $c$ is a smoothness parameter we set equal to a small positive number. ${ }^{15}$ In the limit, as $c \rightarrow 0, Z$ collapses to the piecewise linear function:

$$
Z(x ; \zeta ; 0)=\left\{\begin{array}{lll}
x+\zeta / 2 & \text { if } & x \leq-\zeta / 2 \\
0 & \text { if } & -\zeta / 2 \leq x \leq \zeta / 2 \\
x-\zeta / 2 & \text { if } & \zeta / 2 \leq x
\end{array}\right.
$$

This limit also clarifies that the zone disappears as $\zeta \rightarrow 0, Z(x ; 0 ; c)=x$, and the loss function (15) collapses to the quadratic case.

Given this relationship to the quadratic per-period loss, we refer to the loss function in (15) as zone-quadratic. Figure 1 compares the per-period loss due to inflation for the quadratic and zone-quadratic specification. As shown, the zone quadratic form exhibits a width equal to two percent. Thus, if the point inflation target in the quadratic loss is one percent, the zone quadratic loss implies that per-period losses due to inflation are essentially the same within the zero to two percent range we mentioned earlier in our example and only rise materially when the inflation rate is above $2 \%$ or below $0 \%$.

To examine the implications of such preferences for the optimal policy response to inflation, we solve the policymaker's optimization problem described in section (3) substituting the quadratic loss function (2) with the zone-quadratic specification (15) while maintaining the assumption of a linear structure of the economy. Figure 2 provides a first comparison of the solutions to the linear-quadratic (L-Q) and linear-zonequadratic (L-ZQ) models for a specific but representative set of parameters values. Importantly, this comparison rests on the assumption that the policymaker is faced with a deterministic problem, that is we assume that the variances of the shocks in the inflation and output equations, $e$ and $u$, are equal to zero. While this assumption is immaterial for the optimal policy in the L-Q model, the presence of uncertainty does influence the characteristics of the optimal policy once we deviate from the L-Q

\footnotetext{
${ }^{15}$ When we compute optimal policies numerically we use $c=0.1$, throughout.
} 
model. Thus, we proceed in two steps; first abstracting from the effects of uncertainty and then incorporating them later on.

The four panels in Figure 2 show the optimal policy response to inflation deviations from the target, $\pi^{*}$, for alternative values of the discount factor, $\beta$, and the relative weight on inflation stabilization, $\omega$, in the policymaker's preferences. In the top row we show the myopic case, $\beta=0$, while in the bottom row we employ a discount factor $\beta=0.9$. The right column shows optimal policy for inflation nutters, $\omega=1$, while the left column corresponds to the more balanced case with $\omega=0.5$. In each panel, the thin-solid lines show the optimal policy for the L-Q model and the thick-dotted line the corresponding policy for the L-ZQ model. The latter policies are approximated numerically using the dynamic programming algorithm described in the appendix. Each dot corresponds to a grid point in the approximation. The zone parameter $\zeta$ is set to two percent (as in Figure 1).

As one would expect, the relative curvature of the output and inflation loss in the policymaker's preferences does not matter for the optimal policy when the policymaker is only concerned with inflation deviations from target. As the two panels in the right column indicate, when $\omega=1$ the optimal policy is the same in the L-Q and L-ZQ models and is also independent of the policymaker's discounting factor. ${ }^{16} \mathrm{An}$ important implication is that the optimal policy only exhibits inflation zone targeting characteristics if the policymaker also values output stabilization. This becomes evident once we move away from this extreme case and allow for some weight on output stabilization. As shown in the two panels in the left column when $\omega=0.5$, the L-ZQ model exhibits clear inflation zone targeting behavior.

Another relevant observation is that regardless of the discount factor, the width of the zone remains the same. This width is determined by the parameter $\zeta$ in the zonequadratic loss function. The role of discounting, on the other hand, becomes clear if inflation is outside this zone of inaction. In that situation, policymakers who place more weight on future performance take more aggressive action to bring inflation back within the tolerable bounds implied by the inflation zone.

Of course, compared to the actual practice of inflation targeting central banks which

\footnotetext{
${ }^{16}$ This holds for any positive value of the smoothness parameter, $c$, however small. In the extreme case $c=0$, however, the optimal policy is ill defined when $\omega=1$. This, in turn, is a special result that vanishes once uncertainty is introduced in the model.
} 
make use of target ranges of inflation, the optimal policy in the L-ZQ model discussed above implements the target range rather mechanically. However, this is only because so far we have abstracted from uncertainty. Later on, we also report more realistic, less mechanical cases of inflation zone targeting that also account for uncertainty in the inflation and output equations. Before doing so, however, we examine yet another deviation from the L-Q paradigm that suggests a reason why optimal policy may exhibit inflation zone targeting characteristics.

\section{Non-linear economy and inflation zone targeting}

The second deviation from the linear-quadratic paradigm that we examine involves the structure of the economy. Specifically, we relax the assumption that the inflation process is accurately described by a linear accelerationist Phillips curve. Instead we investigate an alternative specification that can provide a partial rationale for inflation zone targeting even under the hypothesis that policymaker preferences can be reasonably approximated with a quadratic loss function.

Our purpose is not to dispute the usefulness of the powerful presumption of linearity in modeling economic structures. Econometric estimation of macroeconomic models with the limitations of the available time series data is a daunting task even maintaining linearity. Consequently, when it is sufficient to work with a linear approximation, the presumption of linearity may be well advised - even when the underlying structure of the economy is non-linear. However, the potential of non-linearities should not be ignored in investigating optimal strategies for monetary policy when the presence of non-linearities may drastically alter the optimal policy response to inflation. Of course, we do not wish to suggest confidence in the presence of non-linearities in the Phillips curve. Our purpose is merely to investigate the consequences of deviating from the presumption of linearity for the design of optimal policy.

In the case of a Phillips curve such as the one we specified in equation (3) this issue is particularly important because it is the source of a fundamental short-run tradeoff facing policymakers. The slope of the Phillips curve in the linear specification, $\alpha$, determines the "sacrifice ratio", that is, the average cost that a policymaker faces for closing a gap between inflation and its desired target measured in terms of output deviations from the economy's potential. The presumption of linearity implies that the sacrifice ratio is independent of the size of an intended change in inflation in any given period. Equivalently in a dynamic setting, the sacrifice ratio is independent of 
the speed at which a policymaker opts to close an inflation gap of given size.

By contrast, if the Phillips curve is non-linear, the sacrifice ratio varies with the size of the intended change in inflation during a period and thus with the speed of bringing inflation back to its target. This introduces another margin in the policymaker's considerations for designing optimal policy. Specifically, if the sacrifice ratio associated with larger per-period changes in inflation is smaller than the corresponding sacrifice ratio associated with smaller per-period changes, a policymaker can economize on the total cost of disinflation by avoiding a slow and protracted strategy that closes an inflation gap in small steps and instead pursuing bigger per-period improvements. And, for the same reason, if the costs of smaller intended changes in inflation imply increasingly larger sacrifice ratios, a policymaker may opt against incurring the relatively large average output loss that would be required for closing small inflation gaps altogether. This suggests that the optimal policy will deviate from linearity in this case.

Since the slope of the Phillips curve is inversely related to the sacrifice ratio, this argument suggests that the design of optimal policy may exhibit inflation zone targeting characteristics if the Phillips curve is flatter in the case of a small output gap than in the case of a large output gap. A number of reasons suggest that this deviation from linearity may be a reasonable one. When output exceeds the economy's potential, the inflationary tendencies of capacity constraints on prices suggest that the Phillips curve is considerably steeper when production far exceeds potential compared to when excess demand pressures are more benign. This argument implies that the Phillips curve may be convex - especially when the output gap is positive. ${ }^{17}$

On the other hand, as Stiglitz (1997) has pointed out, in monopolistically competitive markets producers may exhibit increasingly greater willingness to adjust prices downwards under conditions of weak demand to avoid being undercut by rival firms. This suggests that the Phillips curve may be concave - especially when output falls below its potential. ${ }^{18}$ Ball's (1994) investigation of the output cost of disinflations based

\footnotetext{
${ }^{17}$ Starting with Baily (1978) a number of authors have studied the policy implications of such a convexity in accelerationist Phillips curves. Laxton, Rose and Tetlow (1993) specifically caution against formulating policy based on the presumption of linearity when the Phillips curve may be convex. Turner (1995), Laxton, Rose and Tambakis (1999) and others have presented evidence suggesting a convex shape for several European countries and the U.S.. Finally, Phillips' (1958) original formulation also exhibited a convex shape.

${ }^{18}$ Eisner (1997) presents empirical evidence for such a concave Phillips curve specification for the U.S..
} 
on data for OECD countries, provides additional support for this view as his results indicate that the sacrifice ratio associated with quick disinflations is substantially smaller than the sacrifice ratio associated with more gradual disinflations.

Although these alternatives suggesting convex and concave Phillips curves may appear conflicting at first, in fact they could be consistent with a Phillips curve that is concave when the output gap is negative and convex when the output gap is positive. Filardo (1998) has recently presented evidence for this possibility in the U.S. ${ }^{19}$ Such a concave-convex relationship between economic activity and inflation is also consistent with discussions regarding the relation of wages and employment pre-dating Phillips' (1958) formulation of the Phillips curve. As documented in Humphrey (1986), Sultan (1957) presented a concave-convex relationship between unemployment and wage inflation suggesting a range of unemployment consistent with near-price stability. Earlier, Tobin's (1955) model of business cycle dynamics defined a floor and a ceiling on the level of employment with the property that while prices remained fairly stable within these bounds, veering outside those bounds resulted in deflation or inflation.

Again, we do not wish to suggest that one could confidently presume that the Phillips curve exhibits such non-linearities. Gordon (1997), for instance, maintains that in the U.S. the Phillips curve is "resolutely linear" (p. 26). However, if the Phillips curve does exhibit a concave-convex shape, then its slope will be smaller when the economy is near its potential than when the economy is far away from that level-exactly the deviation from linearity which introduces inflation zone targeting characteristics in optimal monetary policy.

To illustrate the consequences of a concave-convex shaped Phillips curve for optimal policy, we examine a particularly simple deviation from linearity that nests the linear specification as a special case. Using the zone-generating function $Z$ defined in equation (16), we consider:

$$
\pi_{t+1}=\pi_{t}+\alpha Z\left(y_{t+1} ; \zeta\right)+e_{t+1}
$$

This specification implies that inflation remains essentially stable for a whole range of output gap values with width $\zeta$, instead of only when the output gap is exactly zeroas is the case in the linear model. Outside this range the Phillips curve maintains its

\footnotetext{
${ }^{19}$ Filardo also observed that some of the apparently conflicting results on the shape of the Phillips curve may be due to the fact that many authors impose non-linear specifications for the Phillips curve that rule out the possibility of the concave-convex shape.
} 
usual linear shape. Like the linear Phillips curve, this specification also maintains the symmetry property of the model. ${ }^{20}$ Finally, when $\zeta=0$, this specification collapses to the linear case. In the following we will refer to the specification in (17) as zone-linear.

Figure 3 compares the linear and zone-linear Phillips curves. In the example drawn, the width of the zone, $\zeta$, is assumed to be three percent. Thus, according to this specification, deviations of output from its potential do not exert a noticeable influence on inflation as long as they do not exceed one and a half percent, in absolute value. As drawn, the zone-linear Phillips curve is also steeper than the linear Phillips curve once the output gap veers outside the range of stability. As we will show in section 6 , this feature is consistent with simple estimates of zone-linear and linear Phillips curves based on U.S and Euro area data.

To examine the implications of this deviation from the linear-quadratic paradigm, we solve the policymaker's optimization problem described in section 3 substituting the linear Phillips curve, (3) with the zone-linear specification (17) while maintaining the assumption of quadratic preferences. Figure 4 provides an initial comparison of the solutions to the linear-quadratic (L-Q) and zone-linear-quadratic (ZL-Q) models for the same representative set of parameter values as in section 3. Regarding the Phillips curves, the parameters for both, the linear and zone-linear specification, correspond to the values in figure 3. As with our initial comparisons of the L-Q and L-ZQ models in the previous section, we set the variance of the shocks in the inflation and output equations, $e$ and $u$, to zero. Also in parallel with that comparison, we show optimal policies for the four combinations of values for $\beta$ and $\omega$ that we examined there.

Starting with the right column which shows optimal policy for "inflation nutters", $\omega=1$, again we note that the discount factor becomes irrelevant. As before, the optimal policy is to attempt to bring inflation back to its target within one period. Since the tradeoff facing the policymaker is not the same in the L-Q and ZL-Q models, however, the policy that can achieve this goal is different. With a zone-linear Phillips curve, a substantial opening of the output gap becomes necessary to restore inflation to its target, even if the inflation gap is fairly small. Consequently, the optimal strategy for an "inflation nutter" in the ZL-Q model exhibits a substantially greater propensity for output variability than in the L-Q paradigm. Even a tiny inflation

\footnotetext{
${ }^{20}$ Asymmetries, of course, would introduce an additional element of complexity. For instance the average level of output is no longer independent from its variance in that case.
} 
deviation is met with a substantial policy move.

Turning to the more balanced preferences with $\omega=0.5$, reveals how the ZL-Q model provides a rationale for inflation zone targeting behavior. With a zone-linear Phillips curve, the policymaker opts not to make any progress on the inflation front as long as inflation is contained within a certain distance from the ultimate target, $\pi^{*}$. Perhaps the most striking element of the zone-targeting behavior in the ZL-Q model is the discontinuity of the optimal policy function at the bounds of the optimal inflation zone. $^{21}$ Qualitatively, this element of the optimal policy is the same regardless of the policymaker's discount rate. However, the width of the zone is quite sensitive to the degree of discounting. A myopic policymaker (top left panel) would tolerate inflation deviations from target exceeding five percentage points while a policymaker discounting the future (bottom left panel) would only tolerate deviations of about one percentage point before taking corrective action.

\section{Model parameters for the U.S. and the Euro area}

The two deviations from the conventional L-Q model that we have just examined help us identify possible rationales for adopting monetary policy strategies with inflation zone targeting characteristics. However, to assess the practical significance of these departures from the L-Q framework for optimal monetary policy, we need to conduct such comparisons with alternative models using reasonable parameter values and appropriate measures of the uncertainty policymaker's are faced with due to shocks to inflation and output. To obtain such parameter values for the simple output and inflation equations that define our model we estimate least squares regressions using annual historical data for the U.S. and the Euro area, by which we refer to the 11 countries that have adopted the Euro as of January 1, 1999. ${ }^{22}$ For the U.S. we concentrate on the period from 1960 to 1998. For the Euro area, data limitations restrict us to a shorter period-from 1976 to 1998.

We emphasize that given the simplicity of the dynamic structure of the model we do not wish to suggest that our parameterization could accurately capture the complex

\footnotetext{
${ }^{21}$ Technically the optimal policy is not a function but a correspondence. At the bounds of the zone defined by the policy, the policymaker is indifferent between taking no action against inflation and making concrete progress. With a concave-convex Phillips curve, the Euler equation determining the first order conditions of the value function optimization exhibits multiple zeros whose ranking switches as inflation crosses over the bounds of the zone.

${ }^{22}$ Austria, Belgium, Finland, France, Germany, Ireland, Italy, Luxembourg, Netherlands, Portugal and Spain. The European System of Central Banks also includes the central banks of the EU countries which have not yet adopted the Euro as national currency, Denmark, England, Greece and Sweden.
} 
dynamics as could be described, for instance, by a more detailed quarterly model. Rather, our goal here is merely to provide guidance as to the rough quantitative magnitudes relating to the policy problem we explore. Further, unlike our theoretical formulation of the policy problem, the relevant empirical measures of inflation, the output gap and the interest rate are far from obvious. Thus, it must be understood that the parameter values which we obtain very much depend on the concepts we employ and are limited by the accuracy of the underlying data.

For inflation we use the annual percentage change in the output deflator (Q4/Q4 basis). For the Euro area this measure is obtained by aggregating data for the individual Euro area countries. For the output gap we rely on data from the Congressional Budget Office (CBO) for the U.S. and the Organization for Economic Cooperation and Development (OECD) for the Euro area. ${ }^{23}$ Since the methodologies for constructing these output gap series differ we also try to indicate the importance of this difference for our parameters. To do this, we report additional model estimates based on an output gap for the U.S. provided by the OECD for the 1976-1998 period and compare those estimates with another set based on the CBO series for the same sample. Estimation of the output equation also requires data on the nominal interest rate minus inflation. For the U.S. we employ the annual average of the federal funds rate, deflated by the annual rate of inflation measured as the percent change in the output deflator on a Q4/Q4 basis. For the Euro area, identifying a comparable historical series for interest rates is more problematic since monetary policy differed in the individual countries. Although it is possible to construct an aggregate historical interest rate using comparable rates for the individual countries, it is not entirely clear how to best aggregate these data. While output may be aggregated using relative GDP weights, the weights for the interest rate that are most appropriate for the output equation should reflect the relative importance of the individual country interest rates for influencing aggregate demand in all of the Euro area. Since German monetary policy served as a de facto anchor to several of the other Euro area countries over much of the historical sample, we decided to use German interest rates as an appropriate proxy for the Euro area. ${ }^{24}$ Specifically we use the German call money rate deflated by the annual rate of inflation measured as the percent change in the output

\footnotetext{
${ }^{23}$ See Congressional Budget Office (1999) and Giorno et al. (1995).

${ }^{24}$ Peersman and Smets (1999) provide supporting arguments for this choice.
} 
deflator for Germany on a Q4/Q4 basis.

Table 1 presents the parameter estimates for the output equation. All variables in the regression are measured in percent. Our baseline estimate for the Euro area with data from 1976 to 1998 is shown in column (1). Our baseline for the U.S. with data from 1960 to 1998 using the CBO measure of the output gap is shown in column (4). Columns (2) and (3) show the alternative estimates for the U.S. using the OECD and CBO concepts from 1976 to 1998. As can be seen, the point estimates for both, the persistence parameter, $\rho$ and the interest elasticity, $\xi$, differ by sample and area. By these estimates, the output gap exhibits greater persistence in the Euro area than in the U.S. and also a greater sensitivity to interest rate changes. The residual variance is much smaller for the Euro area than for the U.S.. Comparing columns (2) and (3), estimated for the common 1976-1998 period for the U.S. using the OECD and CBO measures of the output gap, respectively, illustrate how much the choice of output gap measure can influence the parameters of the model.

Next we obtain parameters for the inflation equation. For the same four sample/area combinations we examined for the output equation in Table 1, Table 2 presents estimates of the parameters of the Phillips curve. In the top panel we show parameter values obtained under the assumption that the Phillips curve is linear. The slope parameter for the Euro area (column 1) and our baseline U.S. sample (column 4) do not differ by much. Both imply a sacrifice ratio of about 3 . That is, maintaining the linearity assumption, each additional opening of the output gap by three percentage points changes inflation by one percent. We use these parameters in our L-Q and L-ZQ models.

The bottom panel shows parameter values for the zone-linear specification that we use in the ZL-Q model. Here, in addition to the slope parameter, we need a parameter for the width of the zone over which inflation is not materially influenced by changes in the output gap. To let the data provide information on what an appropriate value for this width might be, we estimated regressions with alternative zone widths, starting with $\zeta=0$ and raising it in 0.1 increments. We then selected the width that resulted in the smallest sum of squared errors. The parameters in the table report the resulting width and slope parameters. To note, this procedure nests the linear specification since it includes the estimate with a zone width $\zeta=0.0$. The data suggest that the zone-linear specification does yield a smaller sum of squared errors although the 
difference can be very small. ${ }^{25}$ However, we do not intend these simple regressions to serve as a horse race between the linear and zone-linear specifications. Our purpose is merely to obtain comparable parameters we can then employ to highlight the policy implications of the difference between the two alternatives. The uncertainty associated with estimating Phillips Curves is substantial. ${ }^{26}$

Using the OECD concept of the output gap suggests a width of about two percent for both the Euro area and the U.S.. With the CBO concept of the output gap, the data suggest a width of about three percent for the U.S.. To some extent, this difference may reflect the fact that the OECD measured output gap is less variable than its CBO counterpart. An important feature is that in every case, the parameter for the Phillips curve slope outside the zone is much larger, about twice as large than the corresponding parameter for the linear Phillips curve.

Figures 5 and 6 show the underlying data and parameterized linear and zone-linear Phillips curves for the U.S. and Euro area respectively. The figures highlight the differences that result from the two models for the shape of the short-run policy tradeoff. Furthermore, they provide visual confirmation that it is difficult to ascertain from the data which one of the two forms may be the more appropriate approximation of this tradeoff.

\section{Inflation Zone Targeting under Uncertainty}

As discussed earlier, central banks that employ target ranges or tolerance levels in the design of their inflation targeting framework typically motivate these zones by pointing to uncertainty and the imperfect controllability of inflation. In the conventional L-Q framework, of course, uncertainty, if it is additive has no effect on the optimal policy, and even if it is multiplicative in nature, it does not change the intrinsic linearity of the optimal policy response. This property no longer obtains in the cases of the zone-quadratic preferences or zone-linear Phillips curves discussed in sections 4 and 5 .

In what follows we investigate the impact of uncertainty due to the price shocks, $e_{t+1}$, in the inflation equation (3) or (17), and due to the demand shocks, $u_{t+1}$, in

\footnotetext{
${ }^{25}$ Alternatively, we could have reported estimates based on non-linear least-squares. The point estimates for $\zeta$ are nearly identical to the ones we report in the four columns of the Table and their corresponding t-statistics are 1.8, 1.6, 2.0 and 2.0.

${ }^{26}$ See also Staiger, Stock and Watson $(1997 \mathrm{a}, \mathrm{b})$ for a discussion of the difficulties involved in estimating Phillips Curves and the implications for monetary policy.
} 
the output gap equation (4) on the optimal inflation zone targeting strategy. We proceed in steps, first introducing only price shocks and then both types of shocks in the model with zone-quadratic preferences and then applying the same procedure to the model specification with the zone-linear Phillips curve.

As baseline parameter values for the inflation and output gap equations we use the parameter estimates based on annual U.S. data from 1960 to 1998 with potential output as measured by the Congressional Budget Office, which were reported in the fourth column of Table 1 and Table 2 respectively. In fact, the optimal policies under certainty that were presented in figures 2 and 4 in the preceding sections were based on those same parameter estimates. Later on we will also compute optimal policies using the parameter estimates based on Euro-area data. In these experiments we concentrate on the case with $\beta=0.9$ and $\omega=0.5$.

Another question is how to obtain estimates of the variance of the demand and price shocks. One option would be to use the standard error of the estimate from the respective regression in Tables 1 and 2 that is based on annual data. However, such an estimate would severely overstate the degree of uncertainty faced by the policymaker that is due to unforeseen shocks. In practice, central banks continuously update their information about output and inflation throughout the year and can base their estimate on many other variables in addition to lags of output and inflation. In the following we use one-half the standard error of the estimated regressions as a measure of the uncertainty due to price and demand shocks. Of course, the choice of one-half is somewhat arbitrary. Some sensitivity analysis is provided in a later section in form of a comparison between the Euro area and the U.S., since the respective regression equations have different standard errors.

\section{Zone-quadratic preferences}

The upper panel of figure 7 shows optimal policies under uncertainty due to price shocks alone, while the lower panel shows the policies that result under uncertainty due to price and demand shocks together. As previously, the horizontal axis corresponds to the observed inflation gap, while the vertical axis denotes the intended or expected output gap in the next period that would result given the interest rate set by the policymaker. As a benchmark for comparison the thin solid line in each panel depicts the optimal policy response for the L-Q specification. It is computed analytically, based on equation (10) and has, of course, exactly the same slope in 
both panels because it is unaffected by the degree of uncertainty. Optimal policies under zone-quadratic preferences are computed numerically using the numerical dynamic programming algorithm described in the appendix. The dashed curve in each panel repeats the dynamically optimal policy with zone-quadratic preferences under certainty from figure 2. The optimal policy under uncertainty is represented by the dotted curve with every dot corresponding to a grid point of the numerical approximation.

A comparison of the dashed and dotted curves in the upper panel shows that the inaction zone, which results from zone-quadratic preferences in the perfect certainty case, disappears once the possibility of unforeseen price shocks is taken into account. Instead, the optimal policy in the presence of such shocks is smoother and responds immediately to small deviations of inflation even though the policymaker is endowed with zone-quadratic preferences. Nevertheless, the optimal policy still exhibits a region of "zone-like" behavior. As inflation deviates more and more from the target rate, policy responds more than proportionally to inflation and the intended output gap increases more than proportionally with the inflation gap. This region of "zonelike" behavior is about as wide as the $2 \%$ zone that is embodied in the policymaker's preferences. A comparison of the dashed and dotted curves in the lower panel shows that the inclusion of demand uncertainty further increases the smoothness of the policy response to small inflation deviations in the "zone-like" region.

The intuition for this result is fairly straightforward. In a world with uncertainty due to unforeseen shocks there is always some probability that a shock pushes inflation outside the range of inflation gaps over which the policymaker with zone-quadratic preferences perceives no relevant welfare loss. To reduce the likelihood of inflation falling outside this zone, the policymaker is willing to open up small output gaps even though inflation is still inside the zone. This result is very much consistent with the practice of central banks who use target ranges but typically emphasize that these ranges are not implemented in a mechanical manner.

\section{Zone-linear Phillips curve}

Figure 8 reports the outcome of a similar exercise under the assumption of a zonelinear Phillips curve. Again, the optimal policy for the L-Q framework is depicted by a thin solid line, the optimal policy under perfect certainty in the case of a zonelinear Phillips curve is represented by the dashed curve and the optimal policy under 
uncertainty is represented by the dotted curve.

A comparison of the dashed and dotted curves in the upper panel of Figure 8 reveals an interesting effect of uncertainty due to unexpected price shocks on the optimal policy. The width of the inaction zone increases with the variance of the price shocks. While the optimal policy under perfect certainty exhibits a zone of a little less than $+/-1 \%$, the optimal policy response which takes into account the possibility of price shocks exhibits an inaction zone that is almost twice as large. The intuition for this result is a bit more complicated. First, as pointed out before, in the case of a zonelinear Phillips curve the sacrifice ratio declines with the size of the output gap. In fact, if the short-run Phillips curve is completely flat in some neighborhood of the natural rate, opening up a small output gap has no effect on inflation. Thus, it is not worthwhile to move to offset small inflation deviations from target. Furthermore, any policy move against larger inflation gaps needs to incur a fixed initial cost in terms of the output gap to reach an output level that results in a disinflationary or inflationary impulse. A policymaker who takes into account the possibility of unexpected shocks to inflation, realizes that even in the case of a somewhat larger inflation gap, there is some probability that inflation will be driven back towards the target by an unexpected shock in a subsequent period. Thus, he is a bit more reluctant to incur the fixed initial cost in terms of the output gap that is needed to return inflation to target by policy action. In other words, the fixed cost creates an option value to wait which will be larger the larger the variance of shocks to the price level. As a consequence, the optimal inaction zone increases with the variance of price shocks. This result is closely related to the option value of postponing irreversible investment decisions (see, e.g. Dixit and Pindyck, 1994).

The lower panel in figure 8 shows the optimal policies in the presence of price and demand shocks. Adding demand uncertainty results in a smoother policy response in the case of the zone-linear Phillips curve. Thus, just as in the case of zone-quadratic preferences under uncertainty, the somewhat mechanical inaction zone is replaced by "zone-like" behavior over a region of inflation gaps. The size of the region over which a "zone-like" policy response is optimal, however, is not sensitive to the variance of demand shocks.

Inflation zone targeting in the U.S. and the Euro area: a simple illustration Next we put all the different ingredients analyzed so far, zone-quadratic preferences, 
a zone-linear Phillips curve, inflation uncertainty and demand uncertainty, together and compute optimal policies using the parameters estimated from annual U.S. data (CBO potential, 1960-98) and from annual Euro area data (OECD potential, 197698). As a measure of the variance of output and inflation shocks we use again half the standard error of the estimated equations. It should be emphasized that one should approach the results of this exercise with caution. Given the extreme simplicity of the baseline model and the scarcity of the data, this exercise should only be interpreted as a simple illustration of inflation zone targeting. Nonetheless, since a number of authors in the inflation targeting literature have advocated the adoption of an inflation targeting framework for the U.S. and the Euro area, it would seem useful provide this simple illustration based on our analysis.

The results of this exercise are displayed in Figure 9. The three panels on the lefthand side show the dynamically optimal policy based on U.S. parameters while the right-hand side panels provide the same information based on Euro area parameters. The top panel on each side reports the familiar relationship between the observed inflation gap and the intended output gap in the next period. The middle and lower panels report the implied optimal response of the real interest rate to the inflation gap given a zero current output gap (middle panel), and the response to the output gap given a zero inflation gap (lower panel). Thus, the middle and lower panel illustrate the response coefficients of the optimal policy rule.

In each panel the solid line corresponds to the optimal policy for the L-Q framework, while the dotted curve represents the dynamically optimal policy when the policymaker has zone-quadratic preferences and the economy is characterized by a zone-linear short-run inflation-output tradeoff. Comparing the top left panel for the U.S. to the bottom panel in figure 10, it becomes apparent that combining the zonequadratic preferences and the zone-linear Phillips curve increases the width of the region of "zone-like" behavior.

As expected, the interest rate response to the inflation gap depicted in the middle panel is a mirror image of the response of the intended output gap. The size of the necessary response, of course, depends on the estimated interest elasticity of aggregate demand, which is rather small in the case of the U.S. estimates. Not surprisingly, given our assumptions, the interest rate response to the current output gap is always linear and coincides with the optimal policy response in the L-Q framework. As shown 
in section 3 it is simply determined by the ratio of the coefficients in the output gap equation. ${ }^{27}$

As far as the Euro area parameters are concerned, we also find that the optimal policy response to inflation exhibits a "zone-like" region. The width of this zone is somewhat smaller than in the U.S. case, primarily because the estimated zone in the Phillips curve is only about $2 \%$ compared to about $3 \%$ in the case of the U.S. data. The optimal policy does not exhibit as much smoothness as in the case of the U.S., and the "inaction" zone is a bit more pronounced. The reason simply is that the chosen value for the standard error of demand shocks is only half of the U.S. value. Finally, the optimal interest rate responses are somewhat smaller in the case of the Euro area, primarily because the estimated interest rate elasticity of demand is twice as large.

\section{Structural Uncertainty}

As a last step, we consider the implications of uncertainty regarding the structure of the economy for optimal policy. Specifically, building on the inflation zone targeting example for the U.S. and the Euro area that we just discussed, we ask how a policymaker should behave if he is uncertain as to whether the relationship between inflation and output in the economy is best described by the linear or zone-linear Phillips curves under consideration. To capture this uncertainty, we simply posit that when the policymaker decides what policy to adopt in period $t$ he holds the view that the output-inflation relationship relevant for period $t+1$ is the zone-linear one with probability $p$ and the linear one with probability $1-p$. For simplicity, we maintain that the probability $p$ remains fixed over time and abstract from the policymaker's possible efforts to reduce this uncertainty through learning. ${ }^{28}$

Figure 10 presents the resulting optimal policies for alternative values of the probability $p$. From top to bottom, the three rows correspond to the values, $0.75,0.5$ and 0.25. As in Figure 9, the panels on the left are based on parameters for the U.S. while the ones on the right are based on parameters for the Euro area. Thus, the top row in Figure 9 which is based on the assumption that the Phillips curve is zone-linear with

\footnotetext{
${ }^{27}$ However, to apply this response appropriately, it is also necessary to take into account the fact that in real-time the output gap is measured with substantial error. See e.g. Orphanides (1998) and Smets (1998).

${ }^{28}$ This approach closely parallels the modeling of multiplicative uncertainty in Brainard (1967) (see Estrella and Mishkin, 1999, for a recent exposition) but differs from the robust control approach in Sargent (1999) and Onatski and Stock (1999). Wieland (1998) illustrates the differences in optimal policy that arise with active learning.
} 
certainty, is directly comparable to the policies shown in Figure 10 and corresponds to the limiting case with $p=1$. As can be seen from Figure 10, even if the policymaker is not certain that he faces a zone-linear Phillips curve, if the presumption of linearity is under significant doubt, policy will exhibit "zone-like" characteristics. Of course, this behavior becomes increasingly muted if greater confidence is placed on the linear specification, that is, for lower values of $p$.

\section{Conclusion}

The success of monetary policy in restoring near price stability over the past decade in many industrialized nations has brought the question of the relevant forces for the design of monetary policy in a low inflation environment to the forefront. When inflation is much higher than the desirable long-run target, there is not much controversy that policy ought to aim for reducing inflation. Once low inflation is achieved, however, finer details need to be worked out. How forcefully should policy lean against shocks that might induce minor deviations of inflation from its desirable long-run target? When is it sensible to employ the blunt force of the monetary instrument to effect changes in aggregate demand with that aim? What is the appropriate level of tolerance for the resulting fluctuations in output and employment?

Conventional analysis of optimal monetary policy has typically rested on the paradigm of quadratic preferences and a linear economy to provide answers to such questions. However, this choice primarily reflects the mathematical convenience embedded in these assumptions and is far from innocuous. Monetary policy practice in several countries which have pursued an explicit inflation-targeting strategy and achieved a low-inflation environment, suggests that the linear-quadratic framework fails to capture some of the practical considerations that influence policy decisions, in particular the use of target ranges instead of point targets.

In this paper we have investigated two alternative deviations from the linear-quadratic paradigm, namely zone-quadratic preferences and a zone-linear Phillips curve. Our analysis suggests that when inflation is near the policymaker's bliss level, a policymaker may want to avoid deliberate attempts at changing aggregate demand that would be necessary for further improvements in inflation performance. As a result policy is characterized by a zone of inaction for small deviations of inflation from target. Alternatively, this policy can be characterized as inflation targeting with a 
"thick" inflation target.

We have also explored the implications of uncertainty due to unforeseen demand and price shocks for inflation zone targeting. First, in the case of zone-linear preferences the zone of inaction is replaced by zone-like behavior, that is, a moderate policy response to inflation inside the zone and a more activist response outside of the zone. Although a policymaker with zone-quadratic preferences faced with a small inflation gap may not yet perceive a significant welfare loss, it is optimal to respond to this inflation gap because of the increased likelihood of inflation falling outside this zone in the future due to unexpected price or demand shocks. Second, in the case of a zonelinear Phillips curve the zone of inaction increases with the variance of price shocks, because the steep cost of small improvements in inflation creates an option value to wait, while demand shocks again induce zone-like behavior with a moderated policy response inside the zone. Finally, we also considered the effect of model uncertainty. Clearly, the available evidence does not allow a clear-cut distinction between the linear and the zone-linear Phillips curve specifications on empirical grounds. We show that if the policymaker assigns some probability to each of the two cases, the optimal policy involves a moderated response to inflation deviations within the zone. In sum, these results indicate that uncertainty provides a possible rationale for central banks that have adopted zone rather than point targets, to respond at least moderately to small inflation deviations within the zone.

It is important to note that we have left many important elements of monetary policy in a low inflation environment out of the analysis by concentrating on a simple stylized model. For example, our model does not capture the appearance of interest rate smoothing and inertia that monetary policy exhibits in many countries (e.g. Sack, 1998, Sack and Wieland, 1999, and Woodford, 1999), and although it takes into account some nonlinearities in the structure of the economy it does not consider the practical concerns that arise from the presence of the zero bound on nominal interest rates in a low inflation environment (e.g. Fuhrer and Madigan, 1997, Orphanides and Wieland, 1998, and Rotemberg and Woodford, 1998). Furthermore, we have maintained the simplifying assumption of adaptive expectations and have abstracted from the possible gains from commitment to maintaining inflation stability that become evident in more forward looking models (e.g. Clarida, Gali and Gertler, 1999; Lengwiler and Orphanides, 1998; Levin, Wieland and Williams 1999; and Woodford, 1999). Introducing rational expectations would bring additional interesting elements 
into the analysis and is a useful extension for future research. For instance, recognition of the increased policy responsiveness outside the inflation zone would have a stabilizing effect on inflation within the zone similar to the type of honeymoon effects discussed in the exchange rate target zone literature.

Our analysis has been normative in nature, simply providing possible rationales as to why it may be sensible for central banks to pursue policies with inflation zone targeting characteristics. Of course, the two rationales studied may not necessarily provide the best motivation for the actual practice of inflation zone targeting as currently implemented. A number of alternative and possibly complementary motivations have been advanced. One argument we discussed earlier is that target zones provide a simple way for communicating unconditional confidence intervals for inflation to the public. Another is that if targets are announced at infrequent intervals and target changes involve some cost, a zone target allows partial adjustment to new information arising in the interim period. Further, an inflation target zone may be used to accommodate transient inflation shocks, as a partial substitute for targeting core inflation. A fruitful avenue for future research would be to provide formal microeconomic foundations for these and other potential rationales for the practice of inflation zone targeting. Finally, as data from the practical experience in various countries accumulate, it would be very interesting to test empirically whether interest rate setting by central banks that have announced zone targets is consistent with the nonlinear decision rules implied by the theory. 


\section{Appendix: The Numerical Dynamic Programming Algorithm}

The algorithm for computing the value function and optimal policy relies on successive application of the functional operator $T$, which is based on the Bellman equation (8) and defines a contraction mapping:

$$
T W=\hat{y i n}^{\operatorname{Min}} \int_{-\infty}^{+\infty} \int_{-\infty}^{+\infty} l(\pi, \hat{y}, e, u)+\beta W\left(\pi^{\prime}(p i, \hat{y}, e, u)\right) f(e) f(u) d e d u
$$

Here $W($.$) denotes a continuous bounded function of the state variable and represents$ an approximation of the value function $V$ in equation (8). $l$ defines the one-period loss function, while $\pi$ and $\pi^{\prime}$ represent this period's and next period's values of the inflation rate-the state variable of this DP problem. $\hat{y}$ is the intended output gap, which is effectively the control variable. Next period's value of the inflation rate, $\pi^{\prime}$, is a function of the intended output gap $\hat{y}$, the current inflation rate $\pi$ and of the shocks to the inflation and output equation, $e$ and $u . f(e)$ and $f(u)$ stand for the normal density functions of these zero-mean, normally distributed shocks.

Successive application of the operator $T$ will generate a sequence of functions $W_{n}$ that will converge to the value function $V$, if $T$ is a contraction mapping. Note that the space of continuous bounded functions is a complete and separable metric space in the sup metric defined:

$$
d\left(W_{n}, W_{n+1}\right)=\operatorname{Sup}_{(\pi)}\left|W_{n}(\pi)-W_{n+1}(\pi)\right|
$$

Standard arguments can be used to show that Blackwell's sufficiency conditions of monotonicity and discounting are satisfied and that $\mathrm{T}$ is a contraction mapping. The proof follows Stokey and Lucas (1989), Chapter 9. The contraction mapping implies that:

$$
d\left(T W_{n+1}, T W_{n}\right) \leq \beta d\left(W_{n+1}, W_{n}\right)
$$

Thus, $T$ has a unique fixed point, $V$, which can be computed by value iteration, that is, by successive application of the operator $T \cdot T_{n} W$ converges to $V$ uniformly as $n \rightarrow \infty$. A convenient starting value $W_{0}$ is the single period loss function $l($.$) .$

It is straightforward to construct an upper bound on the approximation error. If $W_{n+1}=T W_{n}$, then $d\left(W_{n+1}, W_{n}\right) \leq\left(W_{n}, W_{n-1}\right)$ and after iterating $d\left(W_{n+1+i}, W_{n+i}\right) \leq$ 
$\beta^{1+i ،} d\left(W_{n}, W_{n-1}\right)$. This implies an upper bound on the error in approximating $V$ by $W_{n}$ :

$$
d\left(V, W^{n}\right) \leq \sum d\left(W^{n+1+i}, W^{n+i}\right) \leq \frac{\beta}{1-\beta} d\left(W^{n}, W^{n-1}\right)
$$

This bound only depends on the discount factor $\beta$ and the distance between the approximations obtained in the last two iterations. Note also that the time needed for convergence within a maximal error bound can be reduced significantly by introducing policy iterations in between every value iteration.

The numerical algorithm is implemented as follows: first, compute starting values $W_{0}$ for a grid of values of the state variable $(\pi)$ and save them in a table; second, calculate $W_{1}$ by applying the operator $T$ to $W_{0}$ and update said table. This step involves a minimization with respect to the control $\hat{y}$ for each grid point. This minimization in turn requires repeated evaluation of the two integrals in (A.1). The one-period loss function $l($.$) and the transition equation \pi^{\prime}($.$) are known functions and the density$ functions for $u$ and $e$ are normal. Thus the integrals can be calculated using repeated Gaussian quadrature and values of $W_{0}$ from the table, where $W($.$) is evaluated in$ between grid points by bilinear interpolation.

Given an approximation of this integral the minimization problem can be solved by standard numerical optimization procedures. However the search for the minimum requires special care because there may exist multiple local minima. As a consequence there may be kinks in the value function and discontinuities in the optimal policy. In particular, this is the case for the zone-linear specification of the Phillips curve. Therefore we need to use a slow but secure optimization procedure such as golden section search supplemented by a rough initial grid search. For each value of $\pi$, the minimum in $\hat{y}$ constitutes the value of $W_{1}$ at $\pi$ that is used to update the table. The maximum of $\left|W_{1}(\pi)-W_{0}(\pi)\right|$ is used to calculate the upper bound of the approximation error. Finally, this procedure is repeated to obtain $W_{2}$ and so on until the difference between two successive approximations is sufficiently small $(<0.5 \%)$.

The algorithm is programmed in Matlab and the computations were performed on Pentium PC's as well as SUN Unix workstations. For a more detailed discussion of numerical dynamic programming, quadrature, interpolation and optimization methods used in implementing this algorithm see Judd (1998). 


\section{References}

Angeloni, Ignazio, Vitor Gaspar, and Oreste Tristani (1999), "The Monetary Policy Strategy of the ECB," European Central Bank, Manuscript, February.

Baily, Martin Neal (1978), "Stabilization Policy and Private Economic Behavior," Brookings Papers on Economic Activity 1, 1-50.

Ball, Laurence (1994), "What Determines the Sacrifice Ratio," in Mankiw, N. Gregory ed. Monetary Policy, Chicago: University of Chicago.

Ball, Laurence (1999), "Efficient Rules for Monetary Policy," International Finance, 2(1), 63-84, April.

Bernanke, Ben S., and Frederic S. Mishkin (1992), "Central Bank Behavior and the Strategy of Monetary Policy: Observations from Six Industrialized Countries." In Olivier Blanchard and Stanley Fischer, eds, NBER Macroeconomic Annual, Cambridge, MIT Press, 183-238.

Bernanke, Ben S., and Frederic S. Mishkin (1997), "Inflation Targeting: A New Framework for Monetary Policy?" Journal of Economic Perspectives, 11(2), 97-116.

Bernanke, Ben, Thomas Laubach, Frederic Mishkin and Adam Posen (1999), Inflation Targeting: Lessons from the International Experience, Princeton: Princeton University Press.

Blinder, Alan (1997), "What Central Bankers Could Learn from Academics-and Vice Versa," Journal of Economic Perspectives, 11(2), 3-19, Spring.

Blinder, Alan (1998), Central Banking in Theory and Practice, Cambridge, MA: MIT Press.

Blix, Marten and Peter Sellin (1998), "Uncertainty Bands for Inflation Forecasts," Sveriges Riksbank Working Paper Series, No. 65.

Brainard, William C. (1967), "Uncertainty and the Effectiveness of Policy," American Economic Review, 57, 2, 411-25.

Clarida, Richard, Jordi Gali, and Mark Gertler (1999), "The Science of Monetary Policy," Journal of Economic Literature, forthcoming.

Clark, Todd (1997), "Cross-Country Evidence on Long-Run Growth and Inflation," Economic Inquiry, 35(1), January, 70-81.

Congressional Budget Office (1999), The Economic and Budget Outlook, United States Government Printing Office.

Dixit, Avinash, and Robert Pindyck (1994), Investment under Uncertainty, Princeton: Princeton University Press.

Dupasquier, Chantal, and Nicholas Ricketts (1998), "Nonlinearities in the Output-Inflation Relationship," in Price Stability, Inflation Targets and Monetary Policy, Ottawa: Bank of Canada.

Eisner, Robert (1997), "New View of the NAIRU," in Paul Davidson and Jan A. 
Kregel, eds., Improving the Global Economy: Keynesianism and the Growth in Output and Employment, Cheltenham, U.K.: Edward Elgar.

Estrella, Arturo, and Frederic S. Mishkin (1999), "Rethinking the Role of the NAIRU in Monetary Policy: Implications of Model Formulation and Uncertainty," in Taylor ed. (1999).

Filardo, Andrew (1998), "New Evidence on the Output Cost of Fighting Inflation," Federal Reserve of Kansas City Economic Review, 83(3), 33-62, Third Quarter.

Fischer, Stanley (1981), "Towards an Understanding of the Costs of Inflation: II" in The Costs and Consequences of Inflation, Carnegie-Rochester Conference Series on Public Policy, Vol. 15.

Fischer, Stanley and Franco Modigliani (1978), "Towards an Understanding of the Real Effects of Inflation," Weltwirtschaftliches Archiv, 114, 810-832.

Freedman, Charles (1995), The Canadian Experience with Targets for Reducing and Controlling Inflation, in Leonardo Leiderman and Lars E.O. Svennson, eds., Inflation Targets, London: Centre for Economic Policy Research, 19-31.

Fuhrer, Jeffrey and Brian Madigan (1997), "Monetary Policy when Interest Rates are Bounded at Zero," Review of Economics and Statistics, November.

Giorno, Claude, Pete Richardson, Deborah Roseveare, and Paul van den Noord (1995), "Potential Output, Output Gaps and Structural Budget Balances," OECD Economic Studies No. 24, 1, 167-209.

Gordon, Robert (1997), "The Time-Varying NAIRU and its Implications for Economic Policy," Journal of Economic Perspectives, 11(1), 11-32, Winter.

Haldane, Andrew ed. (1995), Targeting Inflation, London: Bank of England.

Heikensten, Lars (1997), Address before the conference of the Stockholm Chamber of Commerce.

Humphrey, Thomas (1986), From Trade-offs to Policy Ineffectiveness: A History of the Phillips Curve, Richmond: Federal Reserve Bank of Richmond.

Judd, Kenneth (1998), Numerical Methods in Economics, Cambridge, MA: MIT Press

Judson, Ruth, and Athanasios Orphanides (1999), "Inflation, Volatility and Growth," International Finance, 2(1), 117-138 , April.

King, Mervyn (1997), "Changes in UK Monetary Policy: Rules and Discretion in Practice," Journal of Monetary Economics, 39(1), 81-97, June.

Krugman, Paul (1991), "Target Zones and Exchange Rate Dynamics," Quarterly Journal of Economics, Vol. 116, 669-682, August.

Laxton, Douglas, David Rose and Robert Tetlow (1993), "Monetary Policy, Uncertainty, and the Presumption of Linearity," Bank of Canada, Technical Report No. 63, August.

Laxton, Douglas, David Rose and Demosthenes Tambakis (1999), "The U.S. 
Phillips Curve: The Case for Asymmetry," Journal of Economic Dynamics and Control (forthcoming.)

Leiderman, Leonardo and Lars E. O. Svensson (1995), Inflation Targets. Centre for Economic Policy Research, London.

Lengwiler, Yvan, and Athanasios Orphanides (1998), "Optimal Discretion," Manuscript, November.

Levin Andrew, Volker Wieland and John Williams (1998), "Robustness of Simple Policy Rules Under Model Uncertainty," in Taylor ed. (1999).

Nicholl, Peter and David Archer (1992), "An Announced Downward Path for Inflation", Reserve Bank of New Zealand Bulletin 55(4):315-23.

Onatski, Alexei, and James Stock (1999), "Robust Monetary Policy Under Model Uncertainty in a Small Model of the U.S. economy," Manuscript, February.

Orphanides, Athanasios (1998), "Monetary Policy Evaluation With Noisy Information," Finance and Economics Discussion Series, 1998-50, Federal Reserve Board, October.

Orphanides, Athanasios, David Small, David Wilcox, and Volker Wieland (1997), "A Quantitative Exploration of the Opportunistic Approach to Disinflation." Finance and Economics Discussion Series, 97-36, Board of Governors of the Federal Reserve System, June.

Orphanides, Athanasios, and Robert M. Solow (1990), "Money, Inflation, and Growth," in Handbook of Monetary Economics, edited by Benjamin M. Friedman, and Frank H. Hahn. Amsterdam: North Holland.

Orphanides, Athanasios, and Volker Wieland (1998), "Price Stability and Monetary Policy Effectiveness when Nominal Interest Rates are Bounded at Zero," Finance and Economics Discussion Series, 98-35, Board of Governors of the Federal Reserve System, June.

Orphanides, Athanasios, and David Wilcox (1996), "The Opportunistic Approach to Disinflation," Finance and Economics Discussion Series, 96-24, Board of Governors of the Federal Reserve System, May.

Peersman, Gert, and Frank Smets (1999), "The Taylor Rule: A Useful Monetary Policy Benchmark for the Euro Area?" International Finance, 2(1), 85-116, April.

Phillips, A. W. H. (1958), "The Relation between Unemployment and the Rate of Change of Money Wage Rates in the United Kingdom, 1861-1957," Economica, 283-299, November.

Rotemberg, Julio and Michael Woodford (1998), "An Optimization-Based Econometric Framework for the Evaluation of Monetary Policy: Expanded Version" NBER Technical Working Paper, 233, May.

Sack, Brian (1988), "Does the Fed Act Gradually? A VAR Analysis," Finance and Economics Discussion Series, 98-17, Board of Governors of the Federal Reserve 
System, March.

Sack, Brian and Volker Wieland (1999), "Interest Rate Smoothing and Optimal Monetary Policy: A Review of Recent Empirical Evidence", Manuscript, Federal Reserve Board.

Sarel, Michael (1996), "Nonlinear Effects of Inflation on Economic Growth," IMF Staff Papers, 43(1), 199-215.

Sargent, Thomas (1999), "Discussion of 'Policy Rules for Open Economies'," in Taylor ed. (1999).

Smets, Frank (1998), "Output Gap Uncertainty: Does it Matter for the Taylor Rule?" BIS Working Paper No. 60, November.

Staiger, Doug, James Stock and Mark Watson (1997a) "How Precise are Estimates of the Natural Rate of Unemployment," in Romer, Christina and David Romer, Reducing Inflation: Motivation and Strategy, Chicago: University of Chicago.

Staiger, Doug, James Stock and Mark Watson (1997b) "The NAIRU, Unemployment and Monetary Policy," Journal of Economic Perspectives, 11(1), 33-49, Winter.

Stevens, Glenn and Guy Debelle (1995), "Monetary Policy Goals for Inflation in Australia," in, Andrew Haldane ed., Targeting Inflation, London: Bank of England.

Stiglitz, Joseph (1997), "Reflections on the Natural Rate Hypothesis," Journal of Economic Perspectives, 11(1), 3-10, Winter.

Stokey, Nancy and Robert Lucas (1989), Recursive Methods in Economic Dynamics, Cambridge, MA: Harvard University Press.

Sultan, Paul (1957), Labor Economics, New York: Henry Holt and Company.

Svensson, Lars E. O. (1997), "Inflation Forecast Targeting: Implementing and Monitoring Inflation Targets," European Economic Review, 41(6), June, 1111-1146.

Svensson, Lars E. O. (1999a), "Price Stability as a Target for Monetary Policy: Defining and Maintaining Price Stability," working paper, March 1999.

Svensson, Lars E. O. (1999b), "Inflation Targeting as a Monetary Policy Rule," Journal of Monetary Economics, forthcoming.

Svensson, Lars E. O. (1999c), "Open Economy Inflation Targeting," Journal of International Economics, forthcoming.

Svensson, Lars E. O. (1999d), "Monetary Policy Issues for the Euro System," Carnegie-Rochester Conference Series on Public Policy, forthcoming .

Sveriges Riksbank (1998), Inflation Report, 2, June..

Taylor, John B. (1979), "Estimation and Control of a Macroeconomic Model with Rational Expectations," Econometrica, 47(5), 1267-86.

Taylor, John B., ed. (1999), Monetary Policy Rules, Chicago: University of 
Chicago.

Thiessen, Gordon (1996), "Towards a More Transparent and More Credible Monetary Policy," Remarks delivered at the École des Hautes Études Commerciales, Montréal.

Tobin, James (1955), "A Dynamic Aggregative Model," Journal of Political Economy, 63(2) 103-115, April.

Turner, David (1995), "Speed Limits and Asymmetric Effects from the Output Gap in the Seven Major Countries," OECD Economic Studies No. 24, 1, 57-88.

Vickers, John (1998), "Inflation Targeting in Practice: The UK Experience," Bank of England Quarterly Bulletin, November, 368-375.

Wieland, Volker (1998), "Monetary Policy under Uncertainty about the Natural Unemployment Rate," Finance and Economics Discussion Series, 98-22, Board of Governors of the Federal Reserve System.

Woodford, Michael (1999), "Optimal Monetary Policy Inertia," Manuscript, January. 
Table 1

Output Equation Parameters

$y_{t}=$ constant $+\rho y_{t-1}-\xi r_{t-1}+u_{t}$

\begin{tabular}{lcccc}
\hline \hline & Euro Area & \multicolumn{3}{c}{ United States } \\
\cline { 3 - 5 }$($ OECD $)$ & $($ OECD $)$ & $($ CBO $)$ & $($ CBO $)$ \\
& $1976-1998$ & $1976-1998$ & $1976-1998$ & $1960-1998$ \\
\hline \multirow{2}{*}{ constant } & 1.07 & $(2)$ & $(3)$ & $(4)$ \\
\cline { 3 - 5 } & $(0.34)$ & $(0.16)$ & 0.54 & 0.64 \\
$\rho$ & 0.77 & 0.47 & 0.64 & $(0.43)$ \\
& $(0.11)$ & $(0.16)$ & $(0.16)$ & 0.63 \\
$\xi$ & 0.40 & 0.32 & 0.23 & 0.23 \\
& $(0.10)$ & $(0.13)$ & $(0.14)$ & $(0.13)$ \\
$\sigma_{u}$ & 0.84 & 1.51 & 1.62 & 1.80 \\
\hline \hline
\end{tabular}

Notes: Estimated with annual data with least squares over the periods shown. Standard errors are in parentheses. The constant term provides an estimate for $\xi r^{*}$. All data are in percent. OECD and CBO refer to source of series used for the output gap, $y$. The real interest rate, $r$, is constructed as the average rate during a year minus the rate of inflation measured as the annual (Q4/Q4) percentage change in the output deflator. 
Table 2

\section{Inflation Equation Parameters}

Linear: $\pi_{t}=\pi_{t-1}+\alpha y_{t}+e_{t}$

ZoneLinear: $\pi_{t}=\pi_{t-1}+\alpha Z\left(y_{t} ; \zeta\right)+e_{t}$

\begin{tabular}{lcccc}
\hline \hline & $\begin{array}{c}\text { Euro Area } \\
(\text { OECD })\end{array}$ & \multicolumn{3}{c}{ United States } \\
\cline { 3 - 5 } & $(1976-1998$ & $1976-1998$ & $1976-1998$ & $1960-1998$ \\
\hline & $(1)$ & $(2)$ & $(3)$ & $(4)$ \\
\hline \hline Linear & 0.34 & 0.39 & 0.31 & 0.31 \\
\hline$\alpha$ & $(0.13)$ & $(0.09)$ & $(0.08)$ & $(0.07)$ \\
& 0.96 & 0.85 & 0.89 & 1.06 \\
$\sigma_{e}$ & & & & \\
\hline ZoneLinear & 2.0 & 1.9 & 3.1 & 2.9 \\
\hline$\zeta$ & 0.81 & 0.59 & 0.53 & 0.60 \\
$\alpha$ & $(0.28)$ & $(0.13)$ & $(0.12)$ & $(0.11)$ \\
& 0.94 & 0.85 & 0.86 & 0.99 \\
\hline \hline
\end{tabular}

Notes: Estimated with annual data with least squares over the periods shown. Standard errors are in parentheses. All data are in percent. OECD and CBO refer to source of series used for the output gap, $y$. Inflation, $\pi$ is measured as the annual percentage change in the output deflator (Q4/Q4 basis.) For the ZoneLinear case, we estimated regressions with alternative zone widths, starting with $\zeta=0$ and raising it in 0.1 increments. The estimates shown reflect the choice of $\zeta$ that resulted in the smallest sum of squared errors. 
Figure 1

\section{Quadratic and ZoneQuadratic Loss Functions}

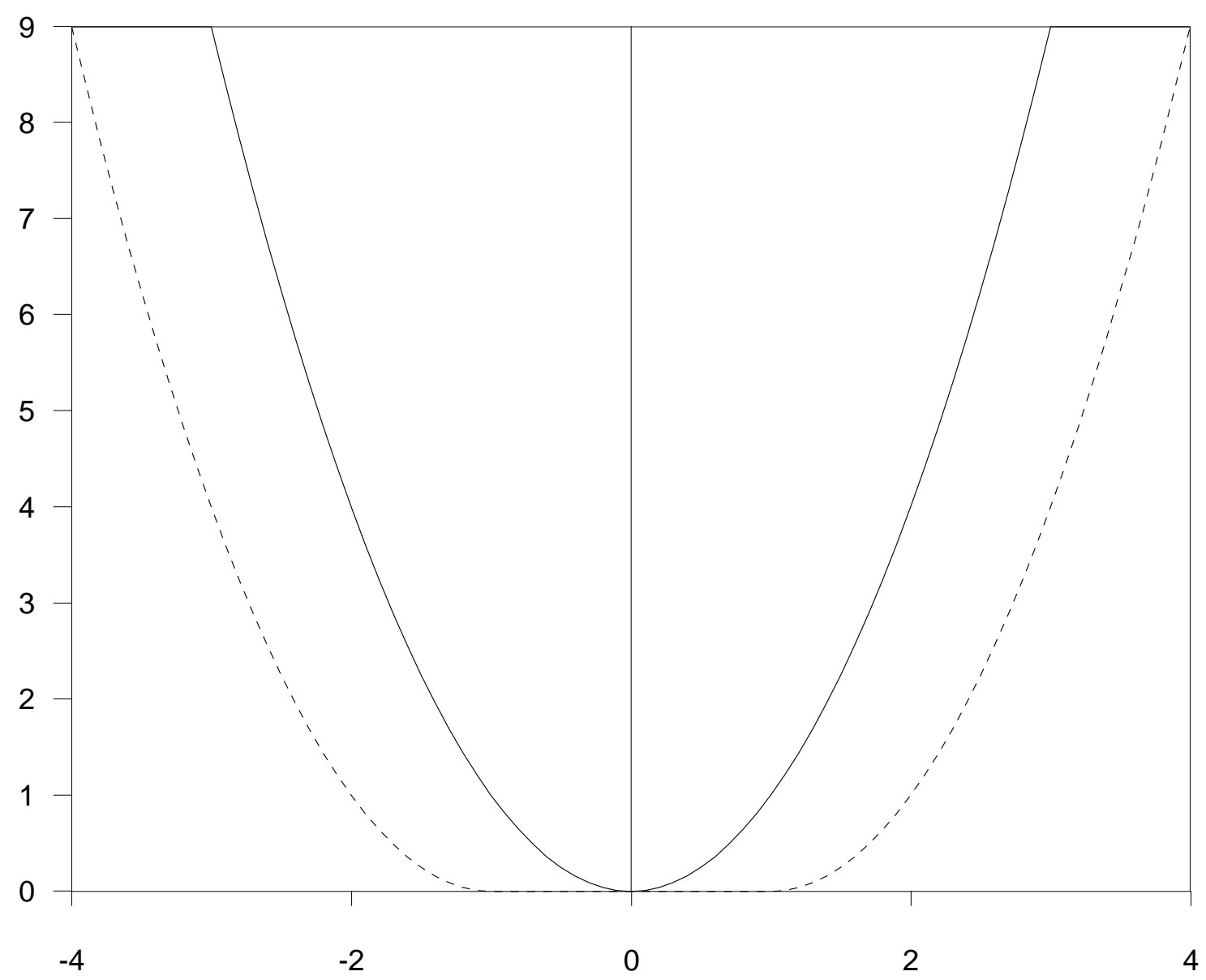

Notes: The solid line plots the quadratic inflation loss, $\left(\pi-\pi^{*}\right)^{2}$. The dotted line plots the zone-quadratic inflation $\operatorname{loss} Z\left(\pi-\pi^{*}, \zeta\right)^{2}$ with a zone width, $\zeta$, of two percent. 
Figure 2

\section{Optimal Policy in the Linear-ZoneQuadratic Model Perfect Certainty Case}
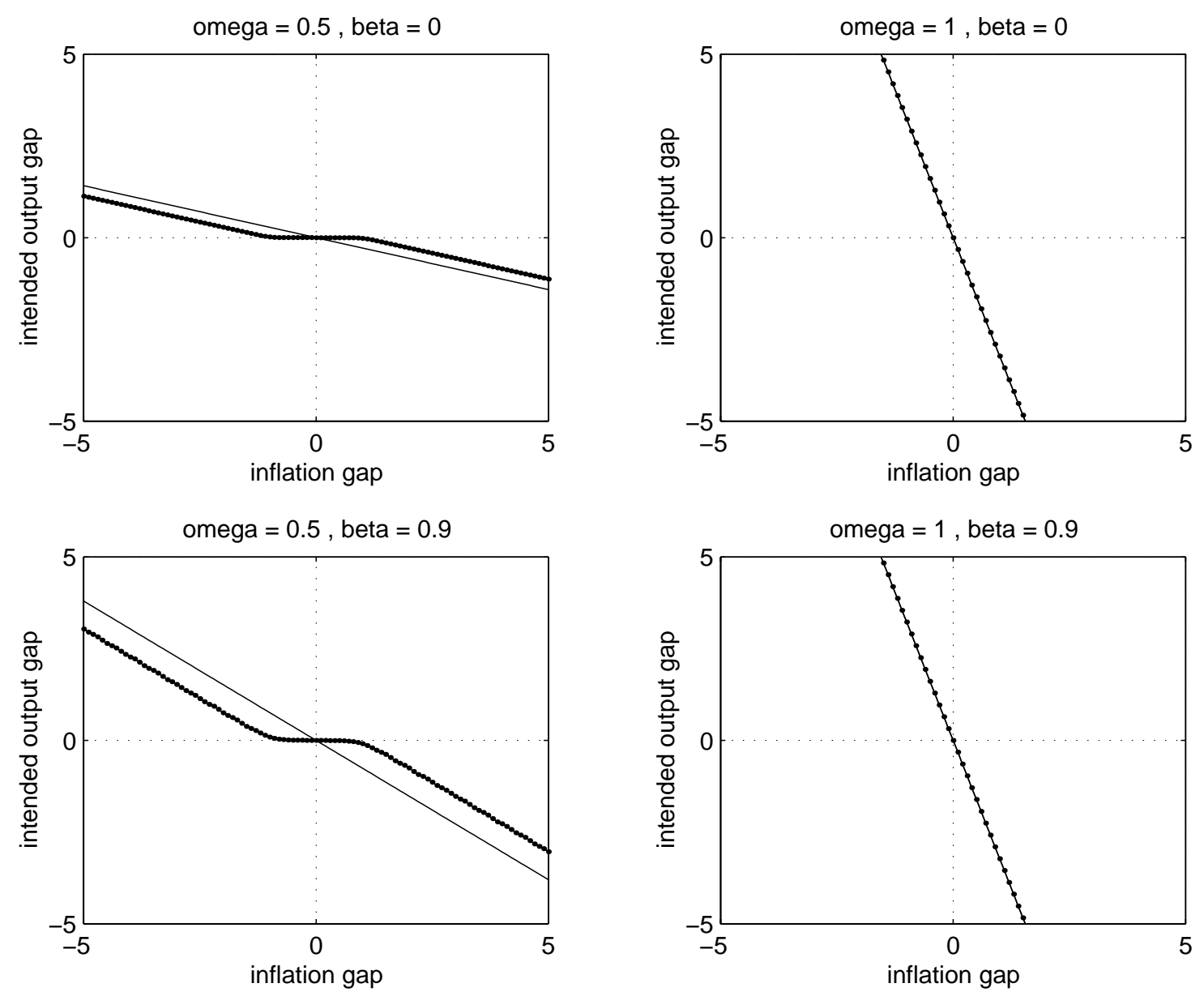

Notes: In each panel the horizontal axis is the state variable, $\pi_{t}$, and the vertical axis the intended output gap, $\hat{y}_{t+1}$. The thin solid line shows the optimal policy for the L-Q model. The dotted line shows the corresponding optimal policy in the L-ZQ model. The top row shows the solution to the static problems $(\beta=0)$ whereas the bottom row shows the solution to the dynamic problem $(\beta>0)$. 
Figure 3

Linear and ZoneLinear Phillips Curves

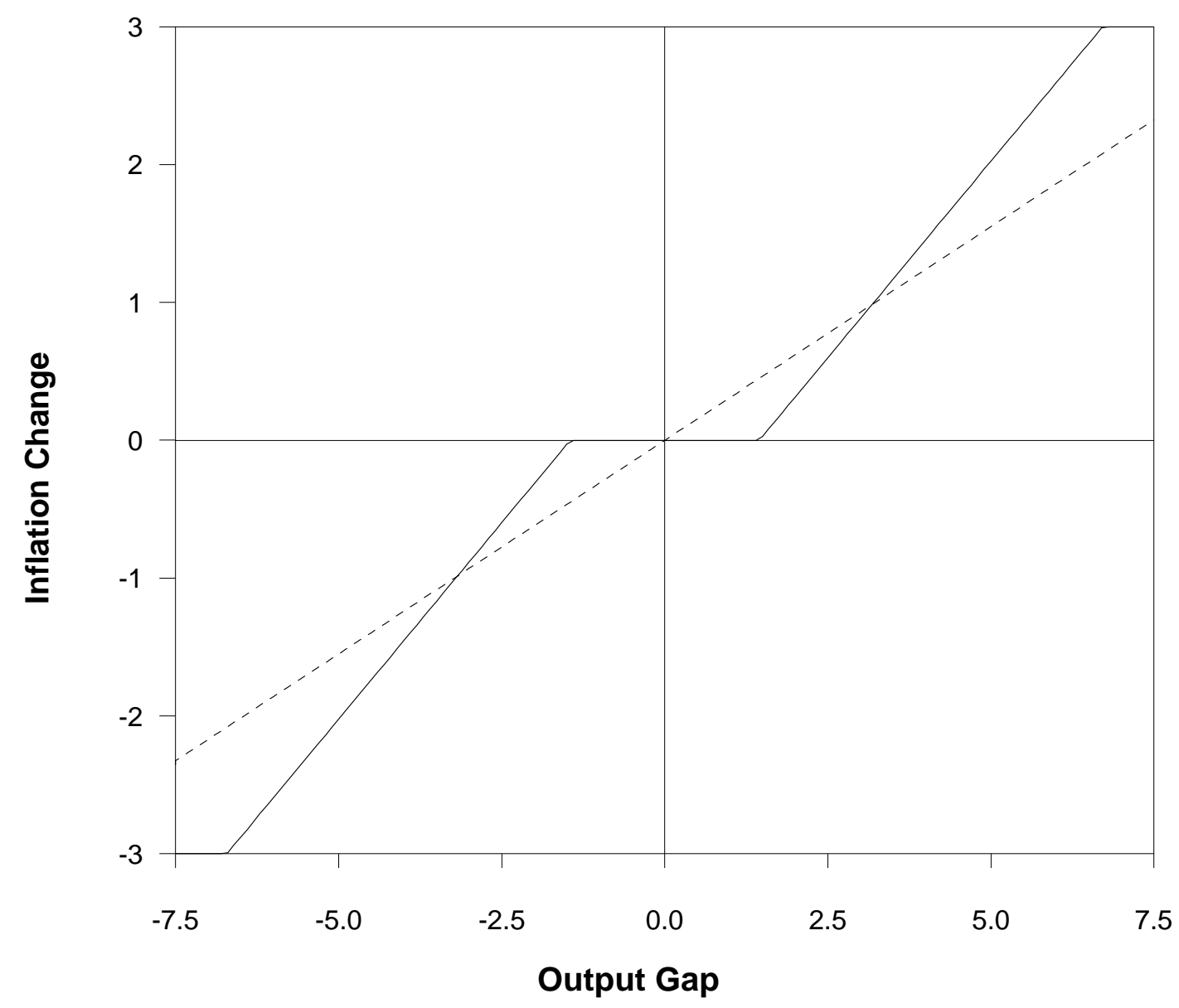

Notes: The dotted line plots the linear Phillips curve $\pi_{t+1}=\pi_{t}+\alpha_{1} y_{t+1}$. The solid line plots the zone-linear Phillips curve $\pi_{t+1}=\pi_{t}+\alpha_{2} Z\left(y_{t+1} ; \zeta\right)$ with a zone width, $\zeta$, of two percent and a slope $\alpha_{2}>\alpha_{1}$. 
Figure 4

\section{Optimal Policy in the ZoneLinear-Quadratic Model Perfect Certainty Case}
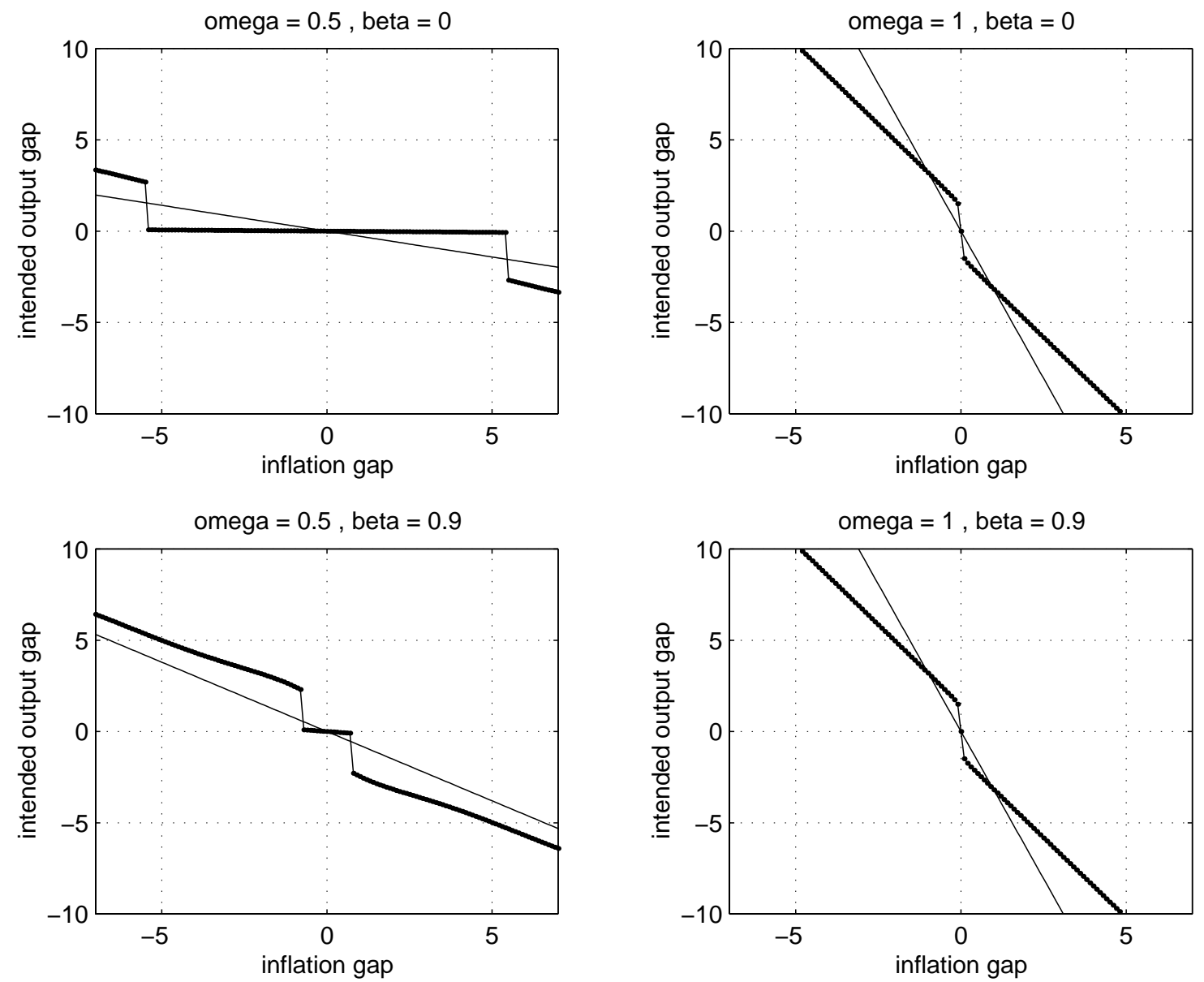

Notes: In each panel the horizontal axis is the state variable, $\pi_{t}$, and the vertical axis the intended output gap, $\hat{y}_{t+1}$. The thin solid line shows the optimal policy for the L-Q model. The dotted line shows the corresponding optimal policy in the ZL-Q model. The top row shows the solution to the static problems $(\beta=0)$ whereas the bottom row shows the solution to the dynamic problem $(\beta>0)$. 
Figure 5

Linear and Zone-Linear Phillips Curve for the U.S. 1960-1998

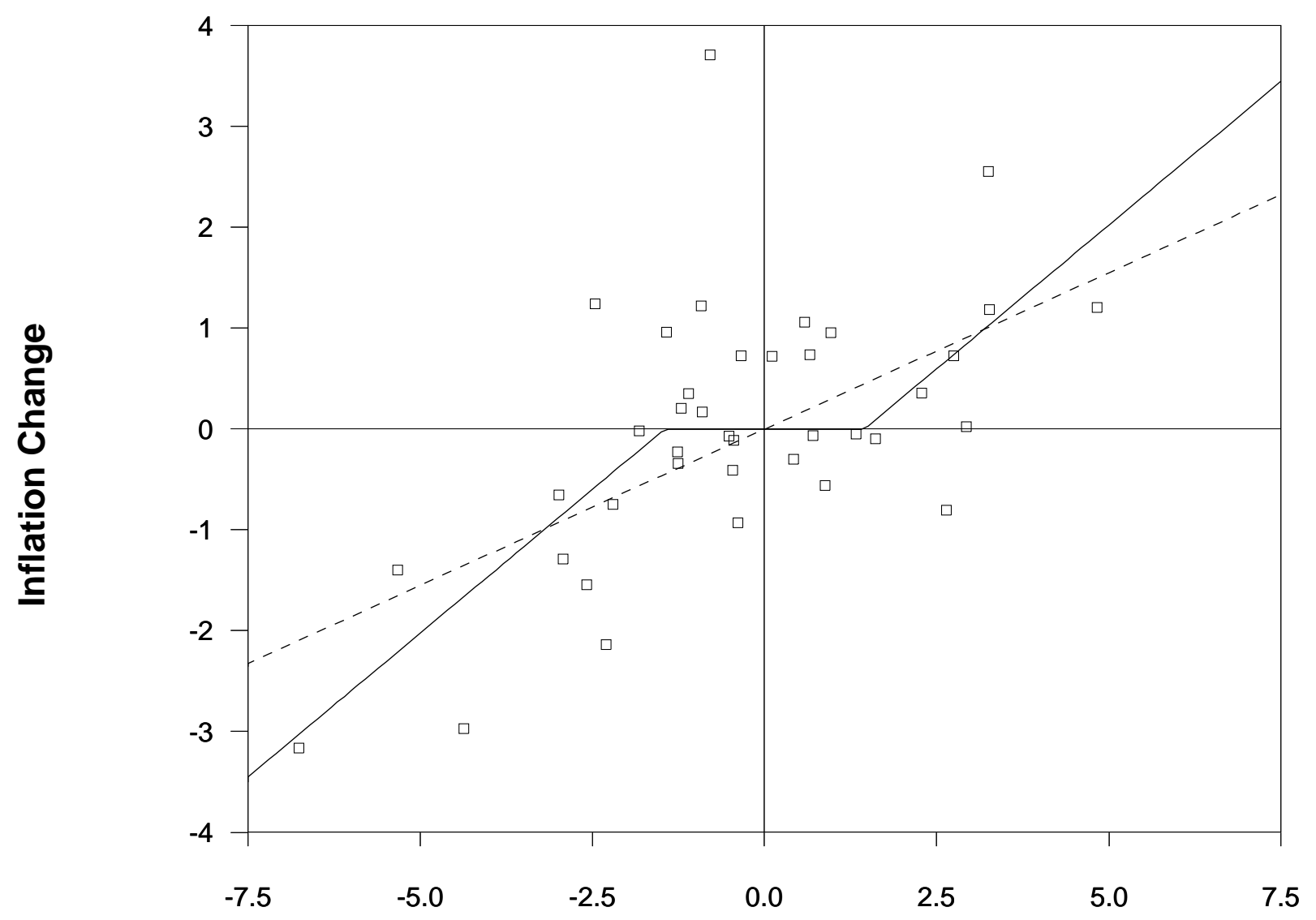

Output Gap 
Figure 6

Linear and Zone-Linear Phillips Curve for the Euro Area 1976-1998

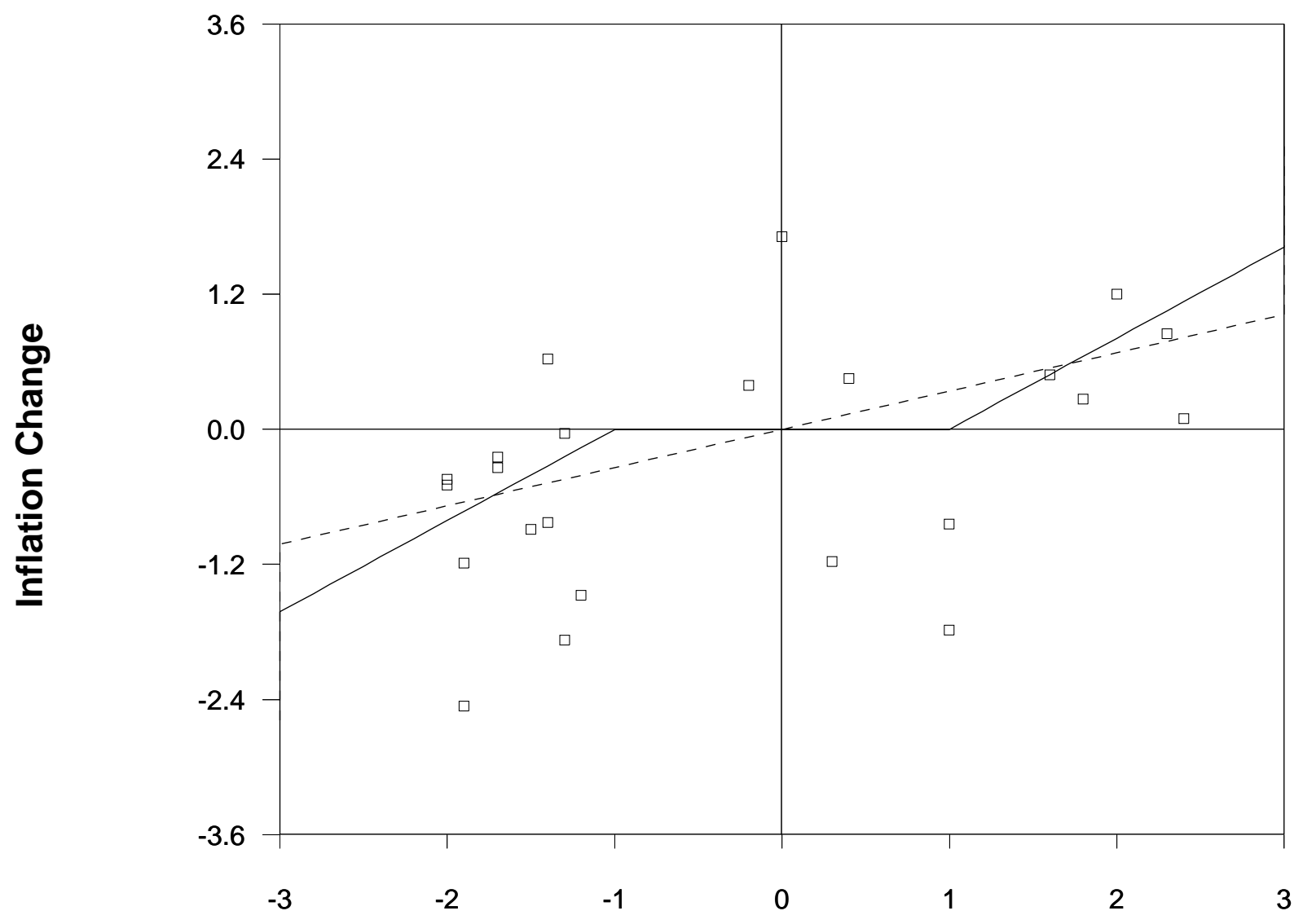

Output Gap 
Figure 7

\section{Optimal Policy in the Linear-ZoneQuadratic Model With Uncertainty}
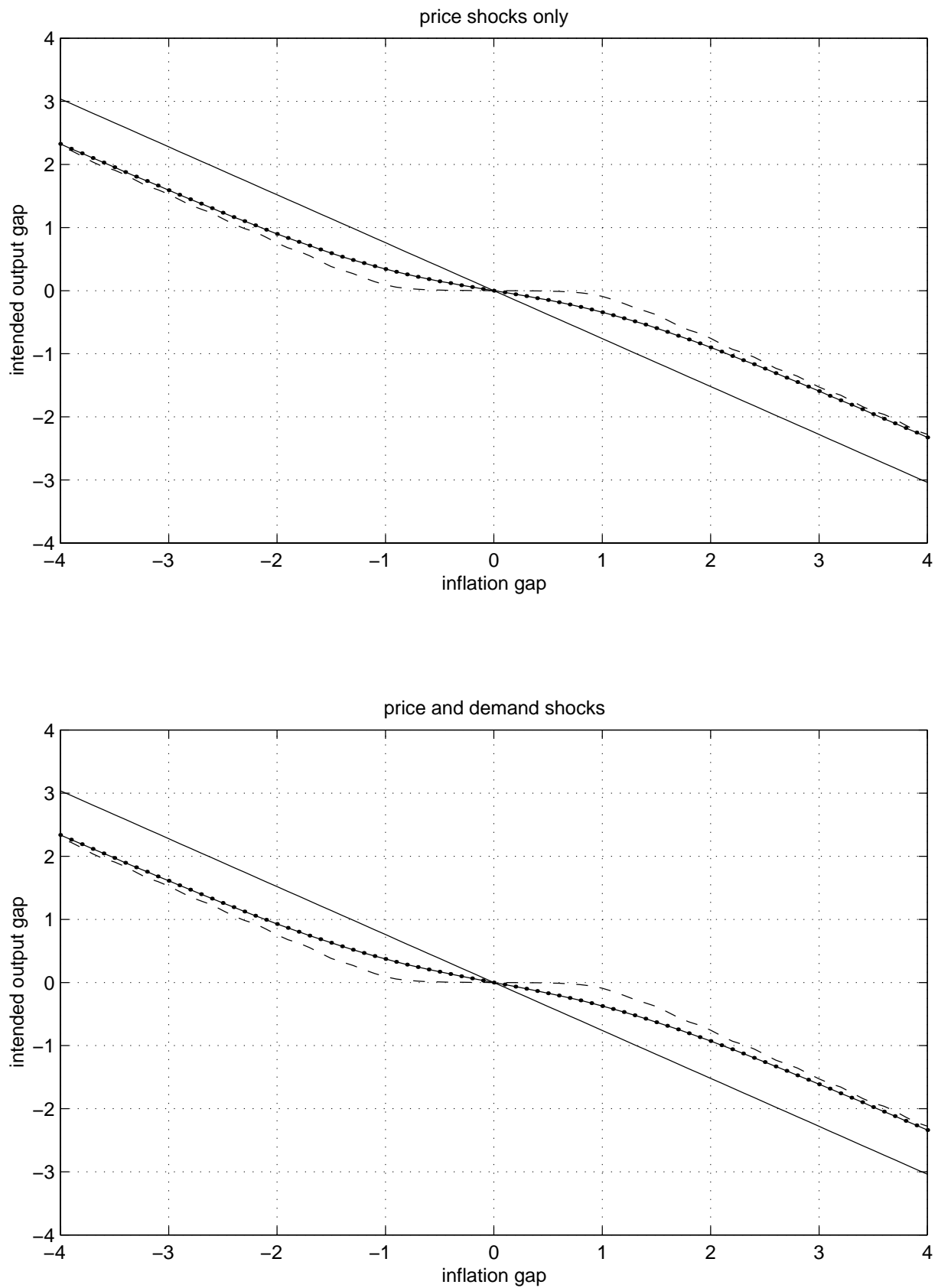

Notes: The upper panel incorporates the uncertainty in the inflation equation only. The lower panel reflects both inflation and output equation uncertainty. The thin solid line shows the optimal policy for the L-Q model. The dashed line shows the optimal policy in the L-ZQ model without uncertainty and the dotted line shows the corresponding optimal policy with uncertainty. 
Figure 8

\section{Optimal Policy in the ZoneLinear-Quadratic Model With Uncertainty}
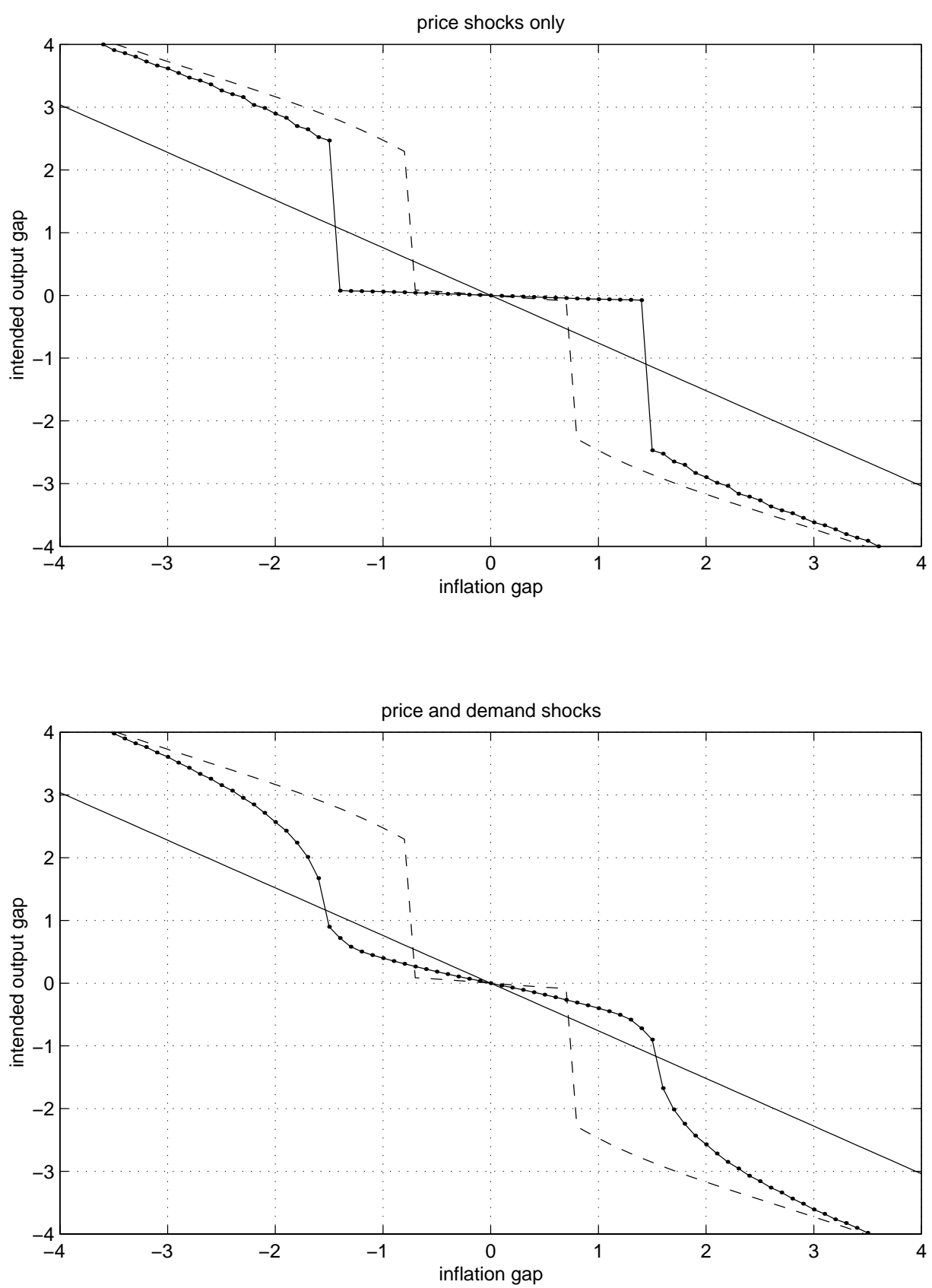

Notes: The upper panel incorporates the uncertainty in the inflation equation only. The lower panel reflects both inflation and output equation uncertainty. The thin solid line shows the optimal policy for the L-Q model. The dashed line shows the optimal policy in the ZL-Q model without uncertainty and the dotted line shows the corresponding optimal policy with uncertainty. 
Figure 9

\section{Optimal Policy in the ZoneLinear-ZoneQuadratic Model With Inflation and Output Uncertainty}
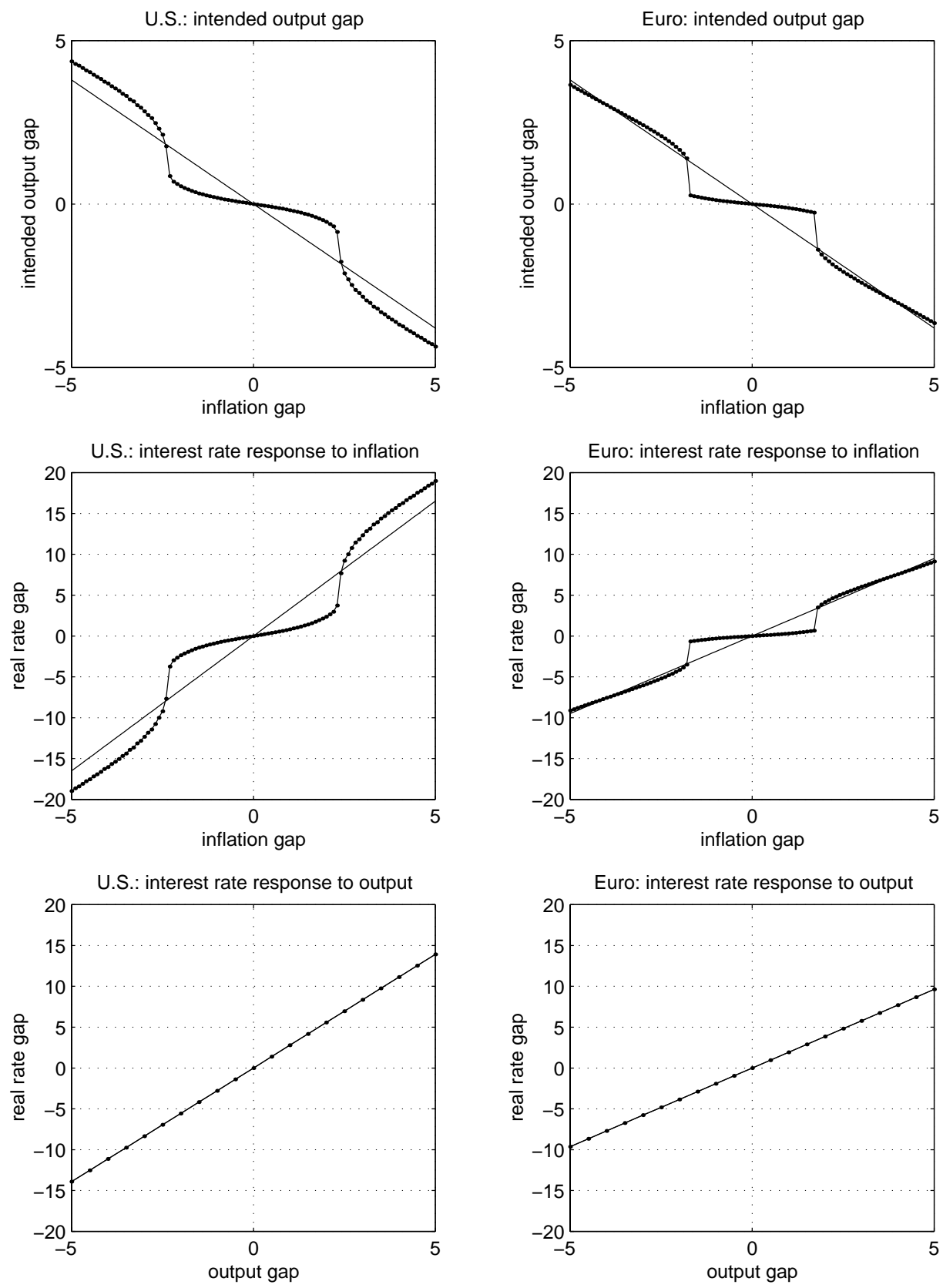
Figure 10

Optimal Policy With Structural Uncertainty
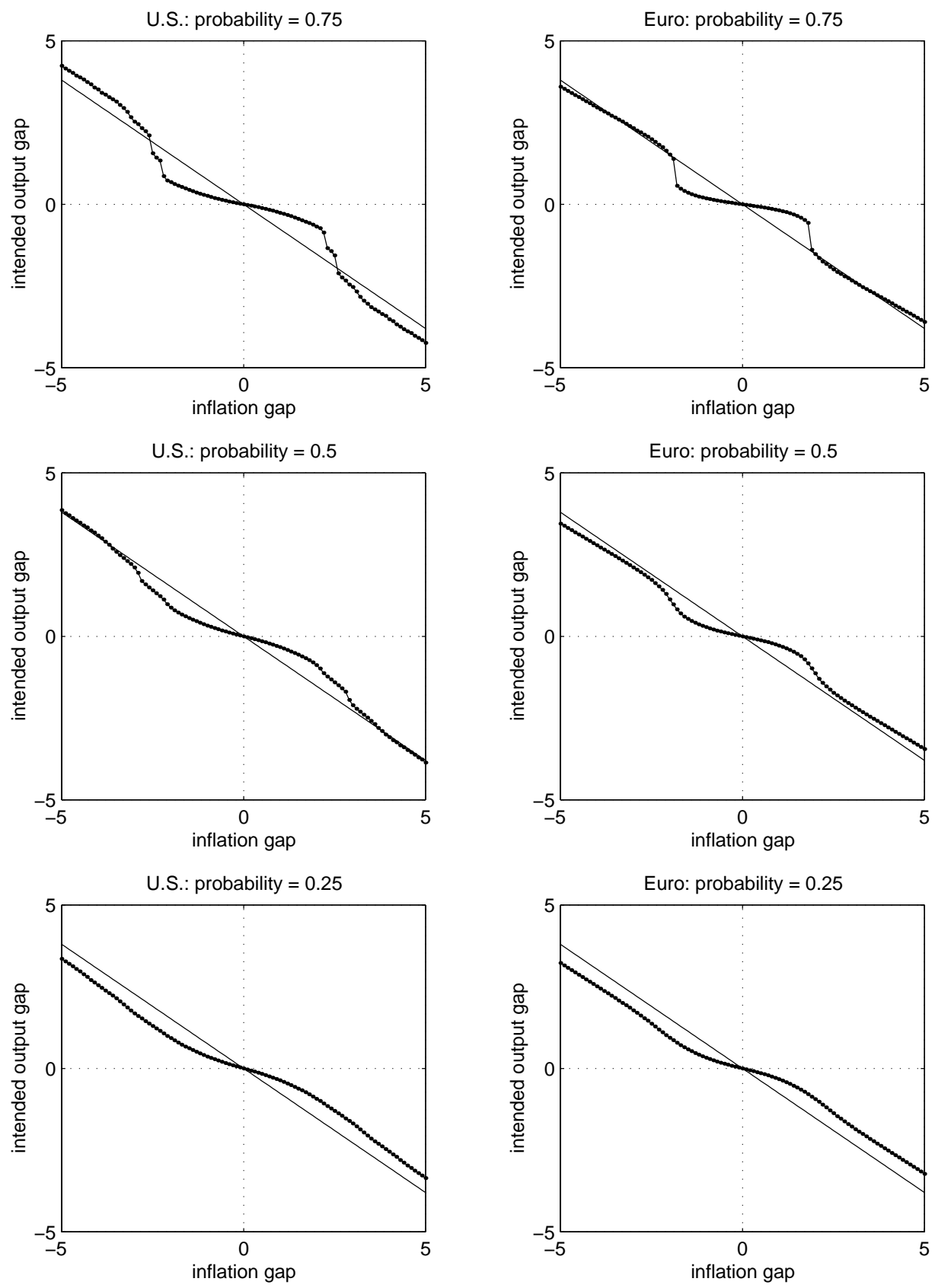


\section{European Central Bank Working Paper Series*}

1 "A global hazard index for the world foreign exchange markets" by V. Brousseau and F. Scacciavillani, May 1999

2 "What does the single monetary policy do? A SVAR benchmark for the European Central Bank" by O. Tristani and C. Monticelli, May 1999

3 "Fiscal policy effectiveness and neutrality results in a non-Ricardian world" by C. Detken, May 1999

4 "From the ERM to the euro: new evidence on economic and policy convergence among EU countries" by I. Angeloni and L. Dedola, May 1999

5 “Core inflation: a review of some conceptual issues” by M. Wynne, May 1999

6 “The demand for M3 in the euro area" by G. Coenen and J-L. Vega, September 1999

7 “A cross-country comparison of market structures in European banking” by O. de Bandt and E. P. Davis, September 1999

8 "Inflation zone targeting” by Athanasios Orphanides and Volker Wieland, October 1999

${ }^{*}$ Publication date in italics 